\title{
New approach in SARS-CoV-2 surveillance using biosensor technology: a review
}

\author{
Dina M. El-Sherif ${ }^{1} \cdot$ Mohamed Abouzid $^{2} \cdot$ Mohamed S. Gaballah $^{1,3} \cdot$ Alhassan Ali Ahmed $^{4} \cdot$ Muhammad Adeel $^{5}$. \\ Sheta M. Sheta ${ }^{6}$
}

Received: 27 August 2021 / Accepted: 13 October 2021 / Published online: 23 October 2021

(c) The Author(s), under exclusive licence to Springer-Verlag GmbH Germany, part of Springer Nature 2021

\begin{abstract}
Biosensors are analytical tools that transform the bio-signal into an observable response. Biosensors are effective for early detection of severe acute respiratory syndrome coronavirus 2 (SARS-CoV-2) infection because they target viral antigens to assess clinical development and provide information on the severity and critical trends of infection. The biosensors are capable of being on-site, fast, and extremely sensitive to the target viral antigen, opening the door for early detection of SARS-CoV-2. They can screen individuals in hospitals, airports, and other crowded locations. Microfluidics and nanotechnology are promising cornerstones for the development of biosensor-based techniques. Recently, due to high selectivity, simplicity, low cost, and reliability, the production of biosensor instruments have attracted considerable interest. This review article precisely provides the extensive scientific advancement and intensive look of basic principles and implementation of biosensors in SARS-CoV-2 surveillance, especially for human health. In this review, the importance of biosensors including Optical, Electrochemical, Piezoelectric, Microfluidic, Paper-based biosensors, Immunosensors, and Nano-Biosensors in the detection of SARS-CoV-2 has been underscored. Smartphone biosensors and calorimetric strips that target antibodies or antigens should be developed immediately to combat the rapidly spreading SARS-CoV-2. Wearable biosensors can constantly monitor patients, which is a highly desired feature of biosensors. Finally, we summarized the literature, outlined new approaches and future directions in diagnosing SARS-CoV-2 by biosensor-based techniques.
\end{abstract}

Keywords Biosensors $\cdot$ SARS-CoV-2 $\cdot$ Detection $\cdot$ Epidemiology $\cdot$ Techniques $\cdot$ Microfluidic

\section{Abbreviations}

AIV A(H7N9)

Avian influenza virus

$\mathrm{A}(\mathrm{H} 5 \mathrm{~N} 1)$

Avian influenza virus subtype strains (low pathogenicity strains)

Avian influenza virus subtype strains (high pathogenicity strains)

Responsible Editor: Lotfi Aleya

Dina M. El-Sherif

dina.moh55@yahoo.com

Mohamed Abouzid

mabouzid@outlook.com

1 National Institute of Oceanography and Fisheries, NIOF, Cairo, Egypt

2 Department of Physical Pharmacy and Pharmacokinetics, Faculty of Pharmacy, Poznan University of Medical Sciences, 60-781 Poznan, Poland

3 College of Engineering, Key Laboratory for Clean Renewable Energy Utilization Technology, Ministry
SARS-CoV-2 Severe acute respiratory syndrome coronavirus-2

SARS Severe acute respiratory syndrome MERS Middle East respiratory syndrome

HAdV Human adenovirus WHO World Health Organization PCR Polymerase chain reaction RT-PCR Real-time polymerase chain reaction

of Agriculture), China Agricultural University, Beijing 100083, People's Republic of China

4 Department of Bioinformatics and Computational Biology, Poznan University of Medical Sciences, Poznan, Poland

5 BNU-HKUST Laboratory of Green Innovation, Advanced Institute of Natural Sciences, Beijing Normal University Zhuhai Subcampus, 18 Jinfeng Road, Tangjiawan, Zhuhai, Guangdong, China

6 Inorganic Chemistry Department, National Research Centre, 33 El-Behouth St., Dokki, Giza 12622, Egypt 


\begin{tabular}{|c|c|}
\hline NA & Nucleic acid \\
\hline RNA & Ribonucleic acid \\
\hline DNA & Deoxyribonucleic acid \\
\hline MIP & Molecularly imprinted polymer \\
\hline LHBB & Luminescent hybridoma-based biosens \\
\hline PAFI & Plasmon-assisted fluoro-immunoassay \\
\hline POC & Point-of-care \\
\hline POF & Portable optical fiber \\
\hline QCM & Quartz crystal microbalance \\
\hline SH-SAW & $\begin{array}{l}\text { Shear horizontal surface acoustic wave } \\
\text { biosensor }\end{array}$ \\
\hline SPR & Surface plasmon resonance \\
\hline LSPR & Localized SPR \\
\hline EBs & Electrochemical biosensors \\
\hline OBs & Optical biosensors \\
\hline PB & Piezoelectric biosensor \\
\hline IS & Immunosensors \\
\hline EZB & Enzymatic biosensors \\
\hline GS & Genosensor \\
\hline WCBs & Whole-cell biosensors \\
\hline MFB & Microfluidic biosensors \\
\hline HRPs & Horseradish peroxidases \\
\hline PAN & Polyaniline \\
\hline BOD & Biochemical oxygen demand \\
\hline CRISPR-Cas9 & $\begin{array}{l}\text { Clustered regularly interspaced short } \\
\text { palindromic repeats-associated protein } 9\end{array}$ \\
\hline SERS & Surface-enhanced Raman scattering \\
\hline PPT & Plasmonic photothermal \\
\hline LOD & Limit of detection \\
\hline LOC & Lab-on-chip \\
\hline $\mathrm{Pe}$ & Péclet number \\
\hline $\operatorname{Re}$ & Reynold's number \\
\hline $\mathrm{Ca}$ & Capillary number \\
\hline LAMP & Loop-mediated isothermal amplification \\
\hline LFDA & $\begin{array}{l}\text { Laminar flow-assisted dendritic } \\
\text { amplification }\end{array}$ \\
\hline MFC & Microbial fuel cell \\
\hline NB & Nano-biosensors \\
\hline MNPs & Metal nanoparticles \\
\hline LFT & Lateral flow test \\
\hline MHealth & Mobile health \\
\hline IL-6 & Interleukin 6 test \\
\hline SAM & Self-assembled monolayers \\
\hline $\mathrm{CBC}$ & Complete blood picture \\
\hline ESR & Sedimentation rate \\
\hline CRP & C-reactive protein \\
\hline CT scan & Computerized tomography scan \\
\hline
\end{tabular}

\section{Introduction}

In the twenty-first century, many respiratory distress such as avian influenza $(\mathrm{A}(\mathrm{H} 7 \mathrm{~N} 9, \mathrm{H} 5 \mathrm{~N} 1))$ and other critical acute respiratory syndromes, among others, have faced humankind, and those have influenced human health and development progress (Narita et al. 2021; Zaidi 2021). At the end of 2019, new severe respiratory distress has spread in China, Wuhan city, and then transferred to the whole world (Nemudryi et al. 2020; Samson et al. 2020; Qiu et al. 2020). Since the World Health Organization (WHO) revealed that coronavirus-2 (SARS-CoV-2) has an etiological agent of the new coronavirus strain epidemic disease, great efforts have been made to discover a vaccine or limit its spread (Barcelo 2020). The spread of SARS-CoV-2 has infected millions of persons in over 213 countries (Suleman et al. 2021), which excited the confirmation of a higher and widespread case more than those that have been appeared since 2003 regarding a severe acute respiratory syndrome (SARS) and in 2012 regarding the middle east respiratory syndrome (MERS) (Wang and Anderson 2019; Wang et al. 2020). Thus, laboratory diagnosis for epidemic prevention and control has been considered one of the foremost priorities. Fast testing diagnosis (e.g., antibody/antigen testing and nucleic acid (NA)-based polymerase chain reaction (PCR) "real-time PCR (RT-PCR)") has frequently been used and developed to cover the epidemic spread (Jin et al. 2020; Li et al. 2020).

In such difficult situations like COVID-19, when healthcare facility professionals are seeking for smart and innovative treatments or selecting a certain type of device for their patients, biosensors play a vital and beneficial function. Biosensors give such chances to more easily and effectively address and handle the difficulties that have previously been raised as well as future concerns. These technologies can be used for illness diagnosis, positive environment providing, monitoring, defense-related toxins, food quality monitoring, prosthetic devices, and medical discoveries (Bahl et al. 2020a).

Additionally, biosensors may convenient to enable the acquisition of both pathogen information in a short time and host response information as well. This could facilitate the prevention process and quick diagnosis for such kinds of viruses as SARS-CoV-2 (Xu et al. 2020; Mao et al. 2020a; $\mathrm{Ma}$ et al. 2021). For instance, novel biosensors such as electrochemical biosensor (EB), optical biosensor (OB), and surface plasmon resonance (SPR) are used for the detection of RNA viruses as "clustered regularly interspaced short palindromic repeats-associated protein 9 (CRISPR-Cas9)" based on a paper strip, nucleic acid-based, aptamer-based, and antigen-Au/Ag nanoparticles (Samson et al. 2020).

Biosensor might be very useful in order to identify and monitor the SARS-CoV-2 virus in the air. It swiftly 
overcomes biological boundaries as well as technical restrictions. This technique aids in determining how long a virus may survive in the air when it is mostly transmitted from person to person. It is also useful for determining whether or not a condition is caused by an infection. It evaluates different laboratory tests and the cause of several infectious diseases in the air automatically (Bahl et al. 2020a).

Additionally, patients who are infected with SARS-CoV-2 have confirmed their viral ribonucleic acid (RNA) in feces (Barcelo 2020). Tetteh et al. (2020) reported that RNA of SARS-CoV-2 and COVID-19 has been detected in the sewage systems which are raising notable concerns about its pathogenic effects on wastewater systems. To date, there is no clear evidence towards SARS-CoV-2 survival in sewage systems or their fate to other ecosystems (WHO 2020); Langone et al. (2021) and other previous reviews revealed the SARS-CoV-2 detection in sewage systems and water environment (Singh et al. 2021). Moreover, the fate of human excreta could be extended to other ecosystems depending on the human pathogenic virus transmission through human body (e.g., mucus, saliva, feces, vomits, urine, and blood) or from a person to another, or indirect/direct contact of contaminated respiratory droplets, or viruses persistence on the surfaces like SARS-CoV-2 (Langone et al. 2021). However, few studies have overviewed this kind of viruses in sewage systems (Table 1), and biosensors gained great attention to be a promising tool for this epidemic.

Therefore, biosensors are miniaturized systems that have a high capacity for development to cover a wide range of usages even on-site (Ejeian et al. 2018; Maryam et al. 2021; Mohankumar et al. 2021). They provide a significant influence on transforming current analytical procedures into diagnostic strategies by restructuring their sensing strategies, improving traditional biosensors with nanotechnology and biotechnology, and detecting various viruses. There are universal applications in healthcare checking, metabolite measurement, illness screening, insulin treatment, clinical psychotherapy, disease diagnosis, medication improvement, and SARS-CoV-2 disease detection (Bahl et al. 2020a). In this review, we summarized the literature, outlined new directions, and explored new approaches and methodologies for SARS-CoV-2 diagnosis and detection using biosensorbased techniques.

\section{Biosensors advantages}

\section{Selectivity}

It is the ability of the biosensor to detect the analyte exclusively. The structures of the viruses are relatively identical, and they have in some cases a nucleic acid genome, a genome-related protein capsid and lipid covering, and a protein layer (Weis et al. 1988). This protein coat helps to distinguish them from the bacteria (Green et al. 1982). Perhaps it can be possible that selective detection of the virus can occur by explicitly identifying and targeting certain capsid proteins with other proteins via protein-protein interactions (Rowe et al. 1999; Rossi et al. 2007; Nidzworski et al. 2014). Typically, adequate selectivity is accomplished by the optimum immobilization of the monolayer of the samples targeting the chosen biomarkers on the sensor surface (Formisano et al. 2015; Miodek et al. 2015). Nanotechnology developments and the speed at which material development and innovation progress give the researchers a solid opportunity to create chemical probes, which are only specific for the target being detected (Ge et al. 2014; Xi et al. 2020). Despite the apparent difficulty in designing specific probes, recent work revealed a probes' surface fouling issues which induced by the blended biomolecules through a network of conductive nanomaterial (Sabaté del Río et al. 2019). Also, after one month of exposure to unprocessed
Table 1 Biosensor-detected respiratory virus in wastewater

\begin{tabular}{llll}
\hline Year & Virus & Biosensor type & Reference \\
\hline 2020 & COVID-19 & POC & Mao et al. (2020a) \\
2016 & Vibrio cholerae & LHBB & Zamani et al. (2016) \\
2015 & Influenza A H1N1 & PAFI & Lee et al. (2015) \\
2015 & Bacteriophage MS2 & MIP and SPR & Altintas et al. (2015) \\
2013 & HAdV & POF & Yildirim et al. (2013) \\
2011 & AIV & Impedance biosensor & Wang et al. (2011) \\
2009 & Influenza A & Piezoelectric-based QCM sensors & Mao et al. (2009) \\
2009 & Porcine Rotavirus & Photonic crystal biosensors & Pineda et al. (2009) \\
2008 & Sin Nombre virus & SH-SAW & Bisoffi et al. (2008) \\
\hline
\end{tabular}

Abbreviations: AIV-avian influenza virus, COVID-19-coronavirus disease, HAdV-human adenovirus, LHBB-luminescent hybridoma-based biosensor, MIP-molecularly imprinted polymers, PAFI-plasmonassisted fluoro-immunoassay, POC-point-of-care, POF-portable optical fiber, QCM-quartz crystal microbalance, SH-SAW-shear horizontal surface acoustic wave biosensor, SPR-surface plasmon resonance 
human plasma, $88 \%$ of the initial interleukin 6 test (IL-6) detection signals were retained.

\section{Sensitivity}

The analyte adhesion on the sensor surface was determined either by the specificity, spacing, and affinity of biorecognition elements or self-assembled monolayers (SAM) (Chaki and Vijayamohanan 2002; Zhou et al. 2006). The transducers (most commonly electric or optical) have also properties that affect the overall biosensor sensitivity (Sethi 1994). If SAM layer specificity is assured, even at a single molecular level, many tiny biomarkers (depths $<150 \mathrm{kDa}$ ) can be identified (Cannon et al. 2012; Wu et al. 2017). The development of the sensor is extremely important to be able to detect biomarkers attributed to pandemic strain, like SARS-CoV-2 in lower concentrations, preferring to the same molecule, and produce an output that can easily be read for the measured/ needed concentration. Any such fundamental problems with the handling of biological liquids on sensor surfaces can also be resolved through additional methods, including sensor instruments using nanoparticles (Nam et al. 2003; Rasheed and Sandhyarani 2015) and microfluid detectors (Puleo and Wang 2009; Tekin et al. 2013).

\section{Response time}

In theory, most sensor transducers respond to the applied stimulus instantly are $(<1 \mathrm{~s})$, such as biomolecular contact with the surface of the sensor (Buerk 1995). However, all of these signals are sometimes necessary to post-process with advanced electrical and computer science systems. The sensor response time is vital for the pandemic to be actively used. For instance, temperature corrections (Hall et al. 2010) and the detection and elimination of background noise (Hall et al. 2013) will also contribute to a greater response time for the sensor. The architecture and function of signal conditional circuits are therefore important in order to ensure a rapid response time.

\section{Multiplexing}

When the characteristics of the viral strain are less widely understood at the early stages of the infection, the infection is frequently signed by the concentrations of common blood biomarkers. For example, in the case of SARS-CoV-2, some hematology and medical investigations such as complete blood picture (CBC), sedimentation rate (ESR), liver functions, $\mathrm{C}$-reactive protein (CRP), and interleukins, in addition to computerized tomography (CT) scan on the chest are performed. A combination of more than two biomarkers is normally used to confirm this condition; therefore, it is an ideal multiplex system for the early detection of the disease that enables multiple biomarkers to be identified. Multiplexing can be accomplished by physically isolating different areas of the sensor area where every isolated region works as a single sensor (Geißler et al. 2010; Li et al. 2018). Moreover, each area may be unique to a single type of biomarker (Varshney and Li 2009; Danilov et al. 2018; Mehta et al. 2018), in which a single transducer scans the isolated areas of the sensor surface, or the addition of several transducers connected to a single sensing area (Formisano et al. 2015; Tort et al. 2017) can be used to measure.

\section{Disposable}

SARS-CoV-2 as an example has a reproductive number that is higher than the calculated for SARS and H1N1, since the single-use sensors needed is between 1.5 and 2 to prevent contamination in sensing systems because pandemic viral strains are highly infectious. The most judicial method for designing a disposable sensor (Wang et al. 2013; Ramfos et al. 2014; Rose et al. 2014) is the modular approach.

Electrodes and readers should be constructed independently in this approach, where electrodes are made costeffective. The use for immobilizing bio probes that are unique in the biomolecules of our interest could potentially become candidates for the creation of disposable electrodes by the use of glass (Zuo et al. 2013), paper (Ge et al. 2014; Desmet et al. 2016), plastic (Kröger and Turner 1997; Farsinezhad et al. 2013), metal (Solanki et al. 2011; Xiao et al. 2012), and ceramic or other material. These products have the best disposable features with paper-based biosensory electrodes (Zuo et al. 2013; Desmet et al. 2016) that have recently attracted public interest. Reading modules in the form of cell phone (Sun et al. 2016) can, on the contrary, deliver many benefits other than cost efficiency, including the frequent processing of data and access to integrated healthcare networks.

\section{Life-time}

The electrodes should also be simple to use and should last at least 1 month. Their simple use can encourage people to self-assess themselves and to make choices on their own self-isolation, essential and knowledgeable, to ensure the spread of disease can be minimized at its source (Gibson et al. 1992; Hannah et al. 2020). This allows for the creation of a variable degree of self-test and self-isolation.

\section{Cost-effect}

Intuitively, the reduced the cost of the biosensor, the much more efficient the system is. The biosensor's cost-effectiveness is expressed in its affordability (Han et al. 2020). In order to maintain the cost lower, so all people in the society 
can tolerate it through disease outbreaks, the biosensor system can even be basically split into 2 parts: its first portion would be a removable electrode, such as a screen-printed electrode or a paper-based electrode, which could potentially be sold in retail pharmacy stores (Yoo and Lee 2010; Choi 2020). The electrode can have direct contact with body fluid. The second component of the sensor device could be a cell phone app that can effectively be used to read signals directly from the sensor (Broeders et al. 2013; Huang et al. 2018). Such applications may theoretically be made available to the government or health authority of the affected area or population.

On the other hand, an autonomous read-only device may even be built for data loggers that can be fitted in hospitals or on a country's border control posts for disposable sensors ( $\mathrm{J}$ et al. 2018). There are definitely several biosensors available in supermarkets, such as paternity checks and side flow strips for sexually transmitting and for disorders already readily accessible. In addition, this will reduce the pressure on public health officials to diagnose the disease in a large population and may also contribute to prompt monitoring of the transmission of the disease.

\section{Mass manufacturable}

During pandemics, there is a pressing and high need for sensors that can specifically and easily diagnose the rapidly spreading outbreak. In SARS-CoV-2, the research rate is limited following the overall population due to an inability to have and meet several sensors and even in countries with the leading public health infrastructures (Dyer 2020; Gaur et al. 2020). In an optimal scenario, the population of a particular geographic area is equivalent to the number of biosensors being studied to ensure that all future communal participants are eligible to participate. While mass production sensors face an important technical challenge, recent production advances, for example, 3D printing (Manzanares Palenzuela and Pumera 2018) and machine molding [158], will lead in a very short space of time to the creation of a large number.

\section{Autonomy and connectivity}

Autonomy in the biosensing process ensures a high degree of reliability between electrodes and reading modules. The pandemic sensor measurement systems should be able, in addition to autonomy, to connect to the central hospital database to capture measurement data in real time. For instance, cellular devices collecting sensor data can be combined with a two-way communication channel to (i) pass data to the central database and (ii) immediately provide therapeutic intervention or facilitate a situation for paramedical staff sent (Cortez et al. 2014; Roda et al. 2016; Wood et al. 2019).

Additional details regarding the responsiveness of a sensor can also be stored and troubleshot by networked healthcare providers. In addition, the central databases could easily be logged on to the venue, positive sickness cases, and personal information, including age, gender, and contact numbers. That will offer real-time intelligence to the government and healthcare policymakers to rapidly and reliably assess appropriate steps, including closing certain areas to avoid and reduce the rapid spread of the epidemic (Ferretti et al. 2020) (Fig. 1).

\section{New approach in SARS-CoV-2 surveillance using biosensor technology}

\section{Electrochemical biosensors}

Electrochemical biosensors (EBs) are a class of biosensors that use an electrochemical transducer to detect biological materials (Osman et al. 2019). EBs were found very effective tools beyond their potential capability to provide a specific quantitative or semi-quantitative analytical information, especially for organic materials; however, many EBs have yet been a widespread success (Riberio et al. 2020). EBs observe the distribution changes over the transducer surface, depending on the potentiometric, amperometric, or impedimetric transduction principles (e.g., enzymes, specific ligands, whole cells, and tissues). Meanwhile, the electrochemical biosensor works on transducing the biochemical events to electrical signals depending on the electrode component as solid support for the immobilization of the biomolecules and electron movement (Cho et al. 2020b).

Accordingly, there are many usages for EB; one of them is detecting the organic pollutants in wastewater through a wide range of biorecognition methods that influence biosensor performance (Ejeian et al. 2018). Notably, the amperometric transduction mechanism based on horseradish baroreceptor was employed, and a modified platinum electrode has also been accomplished by electrostatic attachment of horseradish peroxidases (HRPs) on polyaniline (PAN) (Nomngongo et al. 2012). This implies that a series of innovations for in situ wastewater monitoring concerns pollutants such biochemical oxygen demand (BOD) in very short time per minute with a high detection limit which has been existed or those capable for non-aerated conditions with high detection efficiency (Verma and Singh 2013; Yamashita et al. 2016).

Moreover, due to the recent events of outbreaks concerning the SARS-CoV-2 epidemic since 2019 and others in the last decade, the focus is directed into biosensors as a first crucial step due to their rapid and accurate diagnosis of infected cases (Mao et al. 2020b; Imran et al. 2021). 
Fig. 1 Characteristics of an optimal biosensor for successful pandemic usage

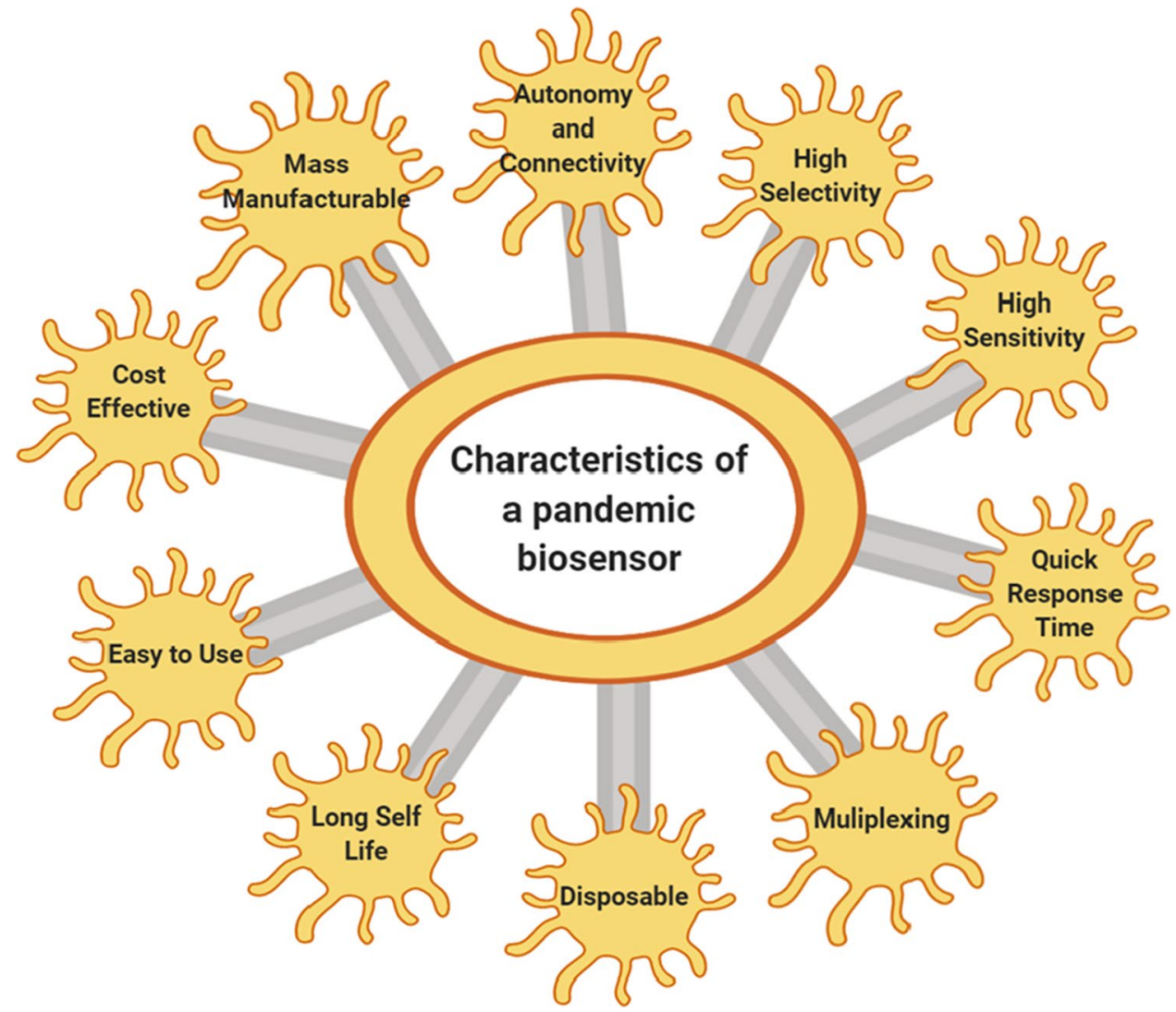

Furthermore, the early stages of SARS-CoV-2 monitoring in wastewater using biosensors could be a likely diagnosis in the current pandemic. Therefore, EBs have a wide application in detecting pathogens, besides the smart option concerning separating electrodes and readout on smartphones (Bhalla et al. 2020; Vidic and Manzano 2021). Because EBs have many advantages (e.g., miniaturization, mass manufacturing, and low cost), they are now becoming widely available in portable formats due to their commercial prices. Thus, the development process to upgrade their use in different fields is running constructively to cover many technologies such as non-labeling techniques which include surface-enhanced Raman scattering (SERS) and quartz-crystal microbalance (QCM) technologies for viral samples or others used for the detection of RNA viruses, such as influenza A/B, SARS-Corona, Ebola, MERS, Zika, and dengue (Loncaric et al. 2012; Han et al. 2016). Moreover, EBs are widely accustomed to detect nucleic acids, proteins, small molecular antibodies, and viruses as noted recently by Barcelo (2020). Besides, EBs have been used many years ago in the detection and diagnosis of viral infections. Due to their low cost, high selectivity and sensitivity (Seshadri et al. 2020), they have been used to detect different influenza A subtypes $\left(\mathrm{H}_{1} \mathrm{~N}_{1}, \mathrm{H}_{5} \mathrm{~N}_{1}\right)$ by using microfluid sensors. Also carbon electrodes sensors have been used to detect MERS and SARS.
For SARS-CoV-2, scientists are using similar techniques as those used to detect SARS infections. A coated transistor (Fig. 2) contains graphene sheets in the presence of SARS-CoV-2 antibodies to produce the desired sensor identification. As well, in another latest research, Mahari et al. (2020) designed three-electrode electrochemical sensors with the presence of carbon electrodes that are able to detect the SARS-CoV-2 viral infection within a limit of 120 $\mathrm{fM}$ in buffer solvent, which shows an additional advantage of electronic biosensors ability to detect viral infection at low concentration (Bhalla et al. 2020). Moreover, EB was developed for SARS-CoV-2 via detection of $\mathrm{S}$ and $\mathrm{N}$ proteins as reported by (Kudr et al. 2021).

\section{Optical biosensors}

There is a large number of biosensors that are based on the plasmonic principle, especially where transduction principles use optical components, for instance, photonic crystals (Rodriguez et al. 2019), waveguides (Ligler et al. 2002), lasers (Ma and Oulton 2019), and fiber optics (Socorro-Leránoz et al. 2019) are classified into optical sensors which are defined as compact analytical tools containing biorecognition sensing element integrated with an optical transducer system (Damborsky et al. 2016). As known, the primary target of the optical biosensor (OB) is to produce a signal 
Fig. 2 Application of carbon electrodes sensors in COVID-19 detection

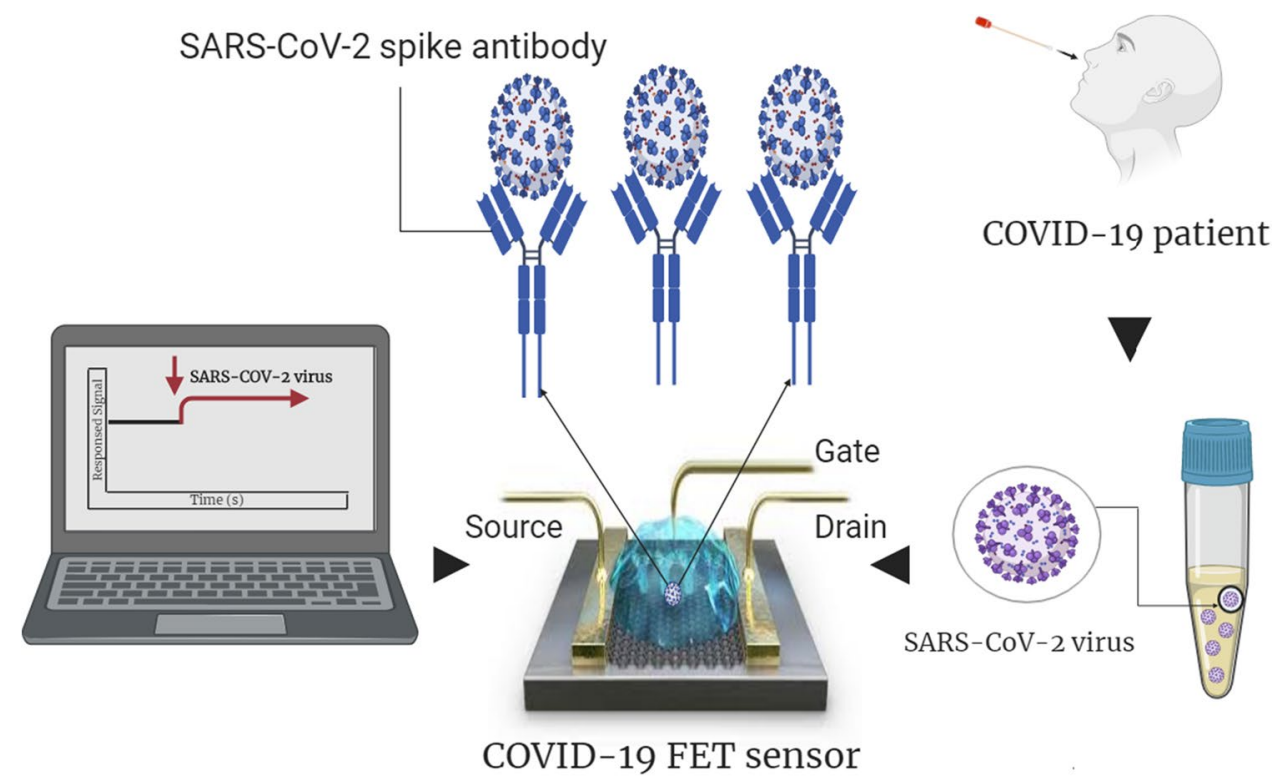

which is commensurable with the concentration of a measured substance (analyte). OB such as localized SPR (LSPR) and SPR were commercially available since the early 1990s (Cooper 2002), and they are used for the detection of viral strains of SARS (Huang et al. 2009), H1N1 (Kamikawa et al. 2012), influenzas (Takemura et al. 2017), and MERS (Lu et al. 2013). Chen and Wang (2020) have described the recent advancement in $\mathrm{OB}$ and focused on the mainstream of research in the biosensor, i.e., SPR, optical resonatorbased biosensor, photonic crystal-based biosensor, optical waveguide-based biosensor, and optical fiber-based biosensor. Those biosensors have a history of epidemic diagnosis detection usage such as Ebola, HIV, and norovirus. This implies their potential ability to be used in nano-scale biosensors for virus detection and single virus imaging (Bhalla et al. 2020).

There are many advantages of the developed plasmonic techniques such as selectivity, short response time, and high sensitivity for the viral strains. However, there are major drawbacks such as high cost and complicated instrumentation being used for plasmonic system development which makes it difficult to use plasmonic techniques in point-ofcare (POC) applications so difficult (Suleman et al. 2021). Therefore, the usage of these sensors remains incomprehensible for self-testing and mass production (Sheta et al. 2019b, 2019a).

The wide applications of the OB have extended to several biological materials which have approved high performance and sensitivity without complexity pretreatment in the detection of the biological system (Damborsky et al. 2016). In addition, they present meaningful progress towards food process control, drug discovery, clinical diagnostics, and even environmental monitoring, which has a desire of combining the detection and imaging to provide a deeper understanding of pathogens and in biological samples as well (Maddali et al. 2020). This feature is allowing pathogen-specific tracers beyond the abnormalities in pathways that concern the disease at the molecular stage. In this regard, the dense biological tissues have a high absorbance potential rate that reduce the light intensity caused a subsequent decrease of the signal-to-noise ratio. This implies the need for advanced tools based on detection and imaging which thoroughly affect the field of $\mathrm{OB}$ to be applied in the further testing mechanism of viral pathogens. As mentioned in the previous part, that biosensors have been applied to detect pollutant levels on wastewater sufficiently and used to observe organic matter based on the immunoanalytical methods, which are known as fluorimetry for signal transducing in OB of organic pollutants (Ejeian et al. 2018), in addition to its common use for other pollutant monitoring in the environment such as antibiotics, hormones, and pesticides.

For the recent SARS-CoV-2 epidemic, OBs have been used in various ways, which present an alternative way for virus detection because of their cost-effective, safe, and not requires a nucleic acid amplification. Pashchenko et al. (2018) concluded that OB-based detection of infectious diseases can be used as POC diagnostic tools having many advantages noted in the previous section. Recently, a deep and great effort has been excited to find a sample tool for detecting viruses such as SARS-CoV-2 or others. For example, Samson et al. (2020) have developed an optical biosensor to detect the virus safely and reliably that combines two different biosensors, one is an optical and another one is thermal. As known, the sensor theory depends on a single RNA strand of the virus detection, in which the receptors are therefore representing the complementary sequences 
that can reliably identify the virus. Moreover, a result in the probability of viruses spreading into wastewater could pose a serious effect on human health. OB has proved their potential ability to detect viruses in wastewater.

A novel biosensor was developed by Qiu et al. to accurately diagnose SARS-CoV-2 where LSPR and plasmonic photothermal (PPT) effects are combined as transduction principles in the sensing scheme (Qiu et al. 2020). Essentially, the DNA receptors are used for the detection of particular SARS-CoV-2 sequences through nucleic acid hybridization. With the compulsory use of nanoparticles and light in LSPR sensing, well-known thermoplasmonic at the plasmonic resonance frequency is being generated. According to the authors, this thermoplasmonic heat increases the in situ hybridization temperature that assists in the accurate distinction of two similar gene sequences. Besides, the LSPR biosensor shows excellent SARS-CoV-2 sequence selectivity with a lower limit of detection (LOD) at a concentration of $0.22 \mathrm{pM}$ (Fig. 3).

\section{Piezoelectric biosensor}

Piezoelectric biosensor (PB) utilizes the piezoelectric effect based on a physical phenomenon of material voltage production upon mechanical stress. This phenomenon can be reversed, and the mechanical stress can be produced upon giving voltage piezoelectric material surface (Narita et al. 2021). In PB, there is a proportional relationship between mechanical stress and the output electric charge. Moreover, fluid pressure is transmitted to a transduction element via pressure sensor diaphragm; hence, there is an additional proportional relationship between the force transmitted and transduction element which is once more converted to proportional electric charge. Piezoelectric effect can be seen in various materials such as anisotropic crystals (crystals without a center of symmetry), quartz, aluminum phosphate, zinc oxide, aluminum nitride, crystalized topaz, lead, barium titanate, gallium orthophosphate, tartrate tetrahydrate, polyvinylidene fluoride, and polylactic acids (Pohanka 2018). In previously mentioned biosensors, transduction and sensing elements can be distinguished, unlike in PB since they are one and the same (Gautschi 2002). PB is widely used in the immunology field to determine numerous macromolecular compounds such as DNA (Kirimli et al. 2014), albuminuria (Muratsugu et al. 2002), and microorganisms such as dengue virus (Chen et al. 2009), and finally for the detection of SARS-C V-2 (Narita et al. 2021).

\section{Immunosensors}

Immunosensors (IS) are biosensor types in which they defined as a combination between a transducer and a biological recognition mechanism. This leads to a generation of a detectable signal associated with the changes in the biomolecule concentrations. There are two main components for this mechanism to occur, the ligand and analyte. The former is covalently immobilized to the matrix, and the latter is passed over the sensor in solution. In IS, the ligands refer to the antibodies, and this technology was first used in the mid1990s for food analysis. Recently, there are many compelling progresses in IS miniaturization. Therefore, portable IS are commercially available enabling on-site and/or simultaneous detection of numerous biomolecules (Dupont 2011). IS have two major categories according to the principle, labeled and non-labeled IS. The design of labeled IS allows the immunochemical complexation (i.e., antigen-antibody complex) to occur on the sensor matrix surface. The immunocomplex formation on the matrix surface has many variations. Therefore, to be able to measure it via optical, potentiometric, and
Fig. 3 A Concentrations of various viral oligos measured using the dual-functional LSPR biosensors, B SPR mechanism, and $\mathbf{C}$ mapping the temperature distribution around the converted PPT heat source.
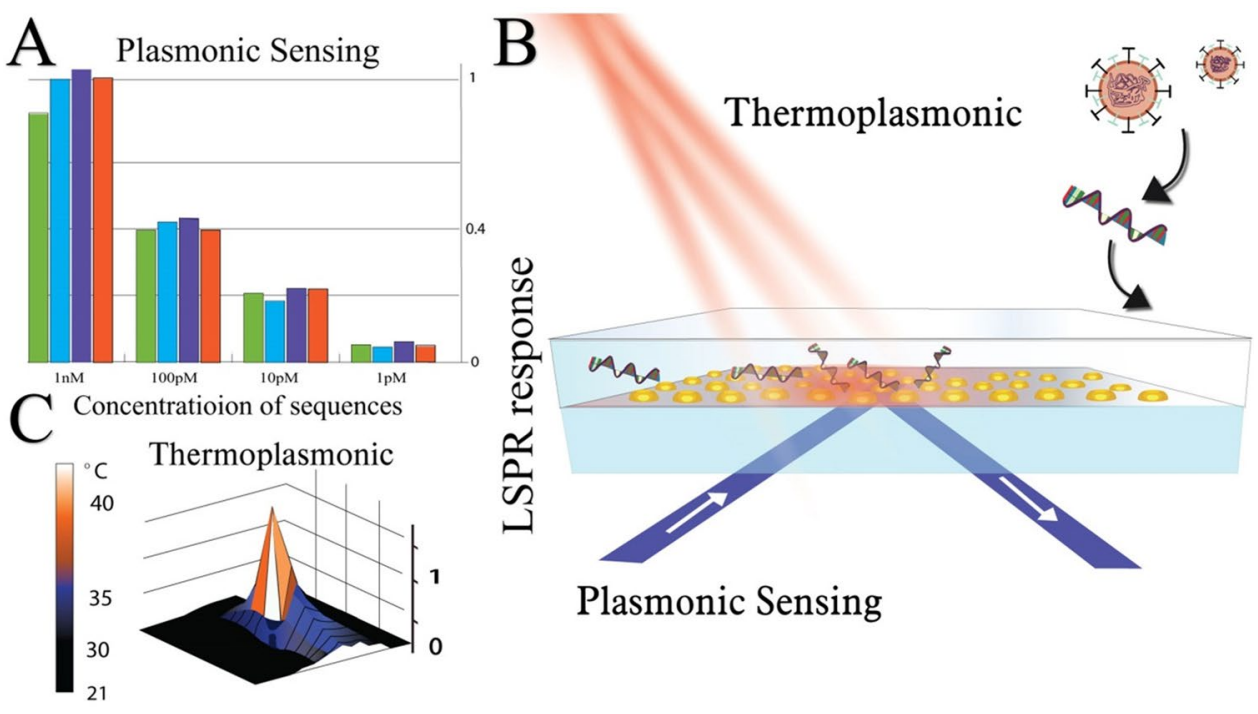
amperometric measurements, the label must incorporate into the immunocomplex in the last step (Fig. 4A).

Unlike labeled IS, the design of non-labeled IS allows the direct determination of immunochemical complexation through measuring the physical changes induced by the formation of the complex. There were many proposed IS as schematically illustrated in Fig. 4B. Solid matrix has either antigen or antibody immobilized on the surface for sensing device formation. In this case, higher sensitivity is required in the solid matrix to detect the immunocomplex formation. Several surfaces can be used to create non-labeled IS (e.g., piezoelectric material, electrode, optically active material, or membrane) (Aizawa 1994). The determination of the antibody or antigen starts by dissolving them in a solution to react with a complementary matrix-bound antibody or antigen for immunocomplex formation. This alternates the surface (e.g., intrinsic piezo-frequency, electrode potential, transmembrane potential) physical properties.

\section{Microfluidic biosensor}

Microfluidic technology became popular in the early 1990s (Manz et al. 1990; Harrison et al. 1992) for chemical separation applications. The technology simplifies fluids' small volume operations in the range of $10^{-6}$ to $10^{-18} 1(\mu \mathrm{L}-\mathrm{aL})$ (Mark et al. 2010; Choi et al. 2012; Puigmartí-Luis 2014). The implementation of microfluidics often utilizes planar substrates bearing enclosed channels with approximate widths, lengths, and depths of $100 \mu \mathrm{m}, 10 \mathrm{~mm}$, and 10 $\mu \mathrm{m}$ scales, respectively. Currently, microfluidic applications have been extended to include synthesis (Baxendale et al. 2006; Baek et al. 2011), genomics (Wu et al. 2014), mazes (Fuerstman et al. 2003; Qin and Wheeler 2007), and music (Tan et al. 2014). The microfluidic community has an integrated lab-on-chip (LOC) system. It is considered a predominantly attractive vision that will reproduce laboratory-scale processes with lower cost, less time, and considerably smaller footprints than their conventional counterparts (Manz et al. 1992). A major difference between microfluidics and conventional systems is that the former depends on fluidic phenomena that show the importance of diffusion, viscosity, and surface tensions. These properties are frequently represented as dimensionless parameters including Péclet number $(P e=\nu L / D)$, Reynold's number $(R e=\rho v L / \mu)$, and capillary number $(C a, v \mu / \gamma)$ where $v$ is the mean fluid velocity, $L$ is a characteristic length in the system, $D$ is coefficient of diffusion, $\rho$ is the fluid density, $\mu$ is dynamic fluid viscosity, and $\gamma$ is surface tension. Generally, $P e, R e$, and $\mathrm{Ca}$ values for microfluidic systems are low, which means, viscous forces dominate inertial forces (resulting in laminar flow), interfacial forces dominate viscous forces, and diffusion dominates convection. It is crucial to consider these phenomena when designing microfluidic systems for biosensors and electrochemistry. This phenomenon at micron length dimensions has been described in detail in previously published books (Tabeling and Chen 2005; Kirby 2010) and reviews (Beebe et al. 2002; Squires and Quake 2005). Examples of microfluidic biosensors (MFB) are displayed in Fig. 5.

Sun et al. have developed a smartphone-based multiplexing nucleic acid detection system integrating a silicon microfluidic chip for loop-mediated isothermal amplification
Fig. 4 A Labeled immunosensors and $\mathbf{B}$ non-labeled immunosensors
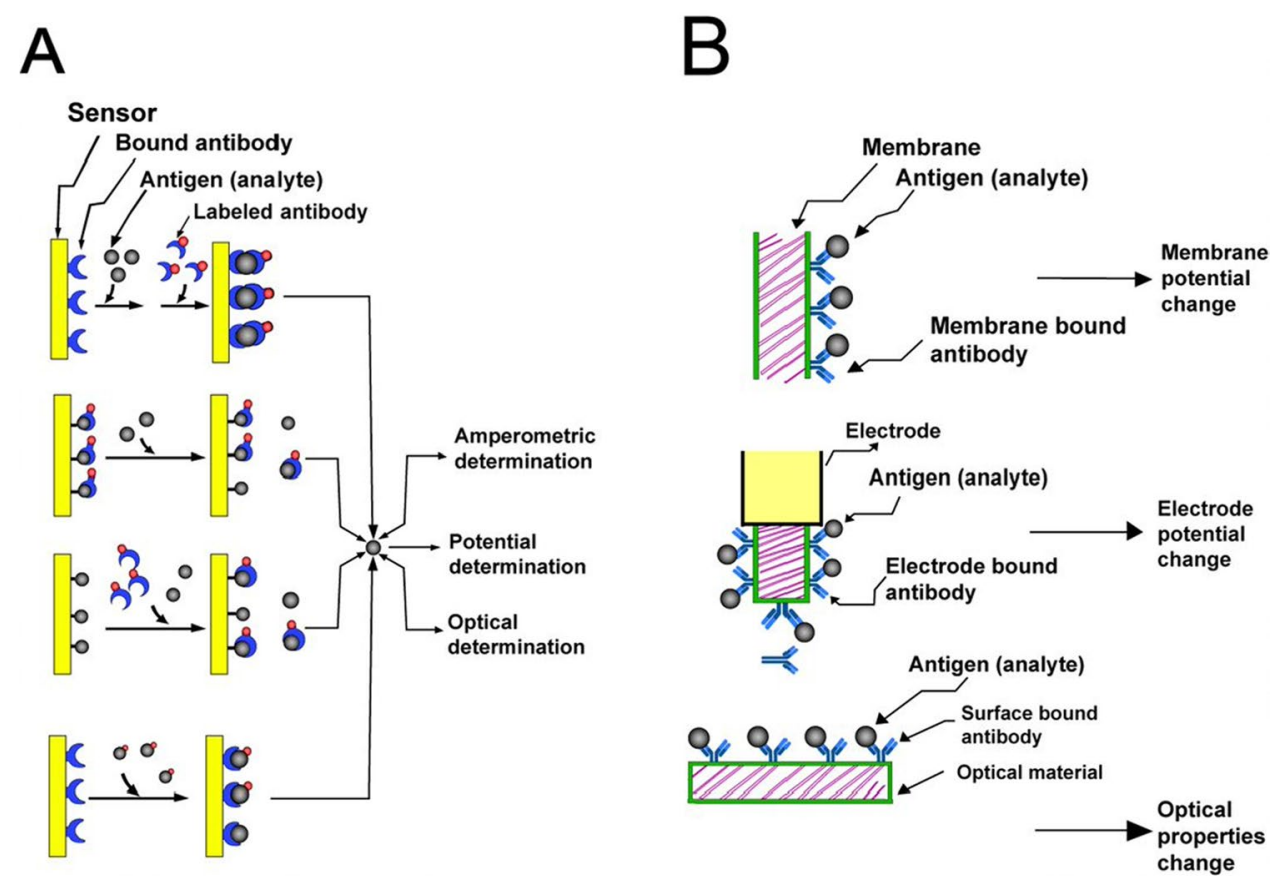

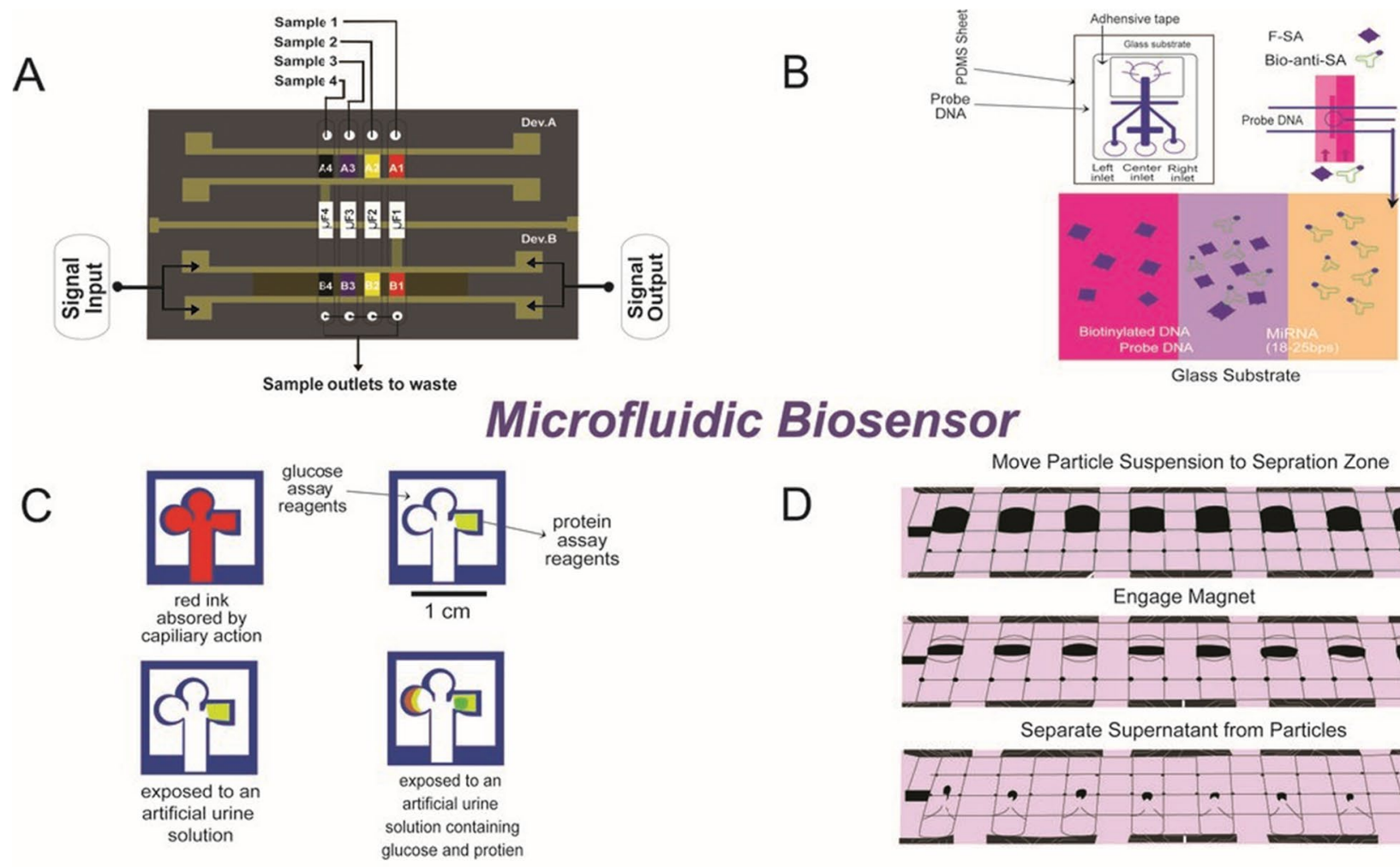

B

Glass Substrate

\section{fuidic Biosensor}

Fig. 5 Microfluidic biosensors. A Surface acoustic wave (SAW) biosensor, B laminar flow biosensor, C paper-based biosensing, and D digital microfluidic-based biosensing

(LAMP) and a smartphone for fluorescence signal detection (Sun et al. 2020). No nucleic acid extraction step was realized on the microfluidic chip, and repeated manual pipetting was required during the assay. Also, Spindiag GmbH (Zengerle and Grötzinger 2020) company is currently developing a centrifugal microfluidic device for SARS-CoV-2 detection due to its short turnaround time. In centrifugal microfluidic biosensors, solutions are transported inside microchannels by spinning-induced centrifugal forces (Gorkin et al. 2010; Kong et al. 2015). Centrifugal microfluidics uses a motor capable of rotating the chips at various speeds, which enables the multi-step mixing of the solution. Therefore, the system has proven its efficacy in multi-nucleic acid testing. A portable centrifugal microfluidic system was developed for H3N2 virus detection (Stumpf et al. 2015).

Mitsakakis and Gizeli developed a surface acoustic wave (SAW) biosensor to apply microfluidic biosensing in microchannels (Mitsakakis and Gizeli 2011). SAW contains dual microfluidic channels and electrical contacts for signal input and output. It is possible to detect four different samples per sensor. Arata et al. developed biosensing in microchannels and laminar flow-assisted dendritic amplification (LFDA) mechanism (Arata et al. 2012). The biosensor was developed by streptavidin-biotin dendrimer complex that is formed by probe-micro-RNA-biotinylated DNA sandwich.
The laminar flow permits the continual addition of biotinylated anti-streptavidin antibodies (green) and fluorescent streptavidin (violet). Martinez et al. developed paper-based biosensing to determine protein and glucose by utilizing two regions. Liquid flow is directed by the hydrophobic patterning via capillary action (Martinez et al. 2007). Finally, Choi et al. reported an application of digital microfluidic-based biosensing showing the separation of the supernatant from magnetic particles by a permanent magnet. It is possible to implement large DMF electrodes and process multiple samples (Choi et al. 2012).

\section{Nano-biosensors}

As known, the nano-biosensors (NB) have a fundamental potential for the future of many diseases' diagnoses. Besides, it collaborates with nowadays technologies to take the diagnosis procedure to a new level (Shirvalilou et al. 2021). Generally, the NB is responsible for detecting biological agents such as antibodies, nucleic acid, pathogens, and other metabolites in the human body. The basic principle of the NB role is based on the affinity of the receptors to binding into the targeting bio-analytes, which in turn modulates the physiochemical signal associated with the binding. Then the transducer has the ability to capture and convert the 
physiochemical signal into an electric signal. The variation in this signal could be measured and monitored, followed by analysis depending on different parameters like current, electric potential, conductance, impedance, mass, temperature, viscosity, and electromagnetic radiation leading to the identification of the presence or absence of the biological agent (Bahl et al. 2020b) (Fig. 6).

Recently NBs are used in the detection of the SARSCoV-2 throughout the viral antigen detection or antibodies detection. For example, graphene is used for that purpose due to the electrical characters with negative charges; also, dendritic nanochips are used as nanomedicine in the determination of $\mathrm{H}_{2} \mathrm{O}_{2}$ in the blood. Metal nanoparticles (MNPs) like gold nanoparticles are also used as they have a potential electric property, excellent biocompatibility, and catalytic properties. The Chinese scientists and researchers developed nanoparticles based on diagnostic kits for rapid testing of SARS-CoV-2. These kits contain 2D materials, graphene, gold nanoparticles AuNPs, and carbon (Antiochia 2020).

\section{Paper-based biosensors}

Paper-based method for detecting SARS-CoV-2 counts as one of the lateral flow tests (LFT), also known as POC, like a pregnancy test. These tests have a similar principle of work as immunoassay technology (Antiochia 2021). The high demand for the POC tests is due to the low cost of the test, ease of use, rapid onset, biodegradability, and proper accuracy (Samson et al. 2020) (Fig. 7).

For SARS-CoV-2 the LFT was designed to detect the presence of human antibodies $\operatorname{IgG}$ and IgM in the patient blood sample. The test strip consists of the following: (i) sample pad, (ii) conjugate pad which has the SARS-CoV-2 antigen conjugated with nanoparticles (as gold), (iii) nitrocellulose membrane with control line coated with $\mathrm{IgG}$ and test line coated with IgM, and (iv) another absorbent pad to absorb the excess sample. Adding the sample will flow along the test device, passing through the conjugate pad, which acts as the first stage if the target antigen is present. It will bind with the stored antibodies IgG forming a colored complex. Then the fluid passes to the nitrocellulose membrane in the second stage, forming a more density color line if the target antigen is present in the sample by binding with IgM antibodies. Finally, the sample reaches out to the absorbent pad, which is the last stage of the test, when the pad will absorb the excess sample amount. The result could be detected as acute infection in the case of a positive (colored) $\mathrm{IgM}$ and negative $\operatorname{IgG}$ or positive at both lines. In contrast, a positive $\operatorname{IgG}$ with a negative IgM indicates a later stage of infection (Choi 2020).

\section{Mobile health (MHealth)}

Mobile health biosensors have a tremendous ability to transcend the disadvantages of a scarcity of therapeutic services to overcome this problem in order to promote successful action. MHealth is the use of mobile devices, materials, and associated infrastructure in the area of health maintenance. MHealth offers an optimal platform for real-time and efficient health maintenance and disease prevention that is accomplished by tailored lifestyle improvements (through interactive applications), community-based or clinical treatment roadmaps, and related diagnosis tracking. MHealth system enhances the efficiency, reliability, and suitability of the integrated healthcare and medical outbreak response, primarily through 2 ways: enhanced access to non-clinical healthcare services (including self-testing) and reporting diagnostic results to medical providers and healthcare organizations (Perkel 2017).

Patients report the findings of the self-tests via the mobile device to the hospital and health services and request assessment and medication recommendations based on the actual state of the patient (Fig. 8). These processes include the quick
Fig. 6 Schematic diagram of nanomaterial-based affinity biosensor for coronavirus detection (AuNPs, gold nanoparticles; GR, graphene; NWs, nanowires; AuNIs, gold nickel nanoparticles; FET, field-effect transistor)

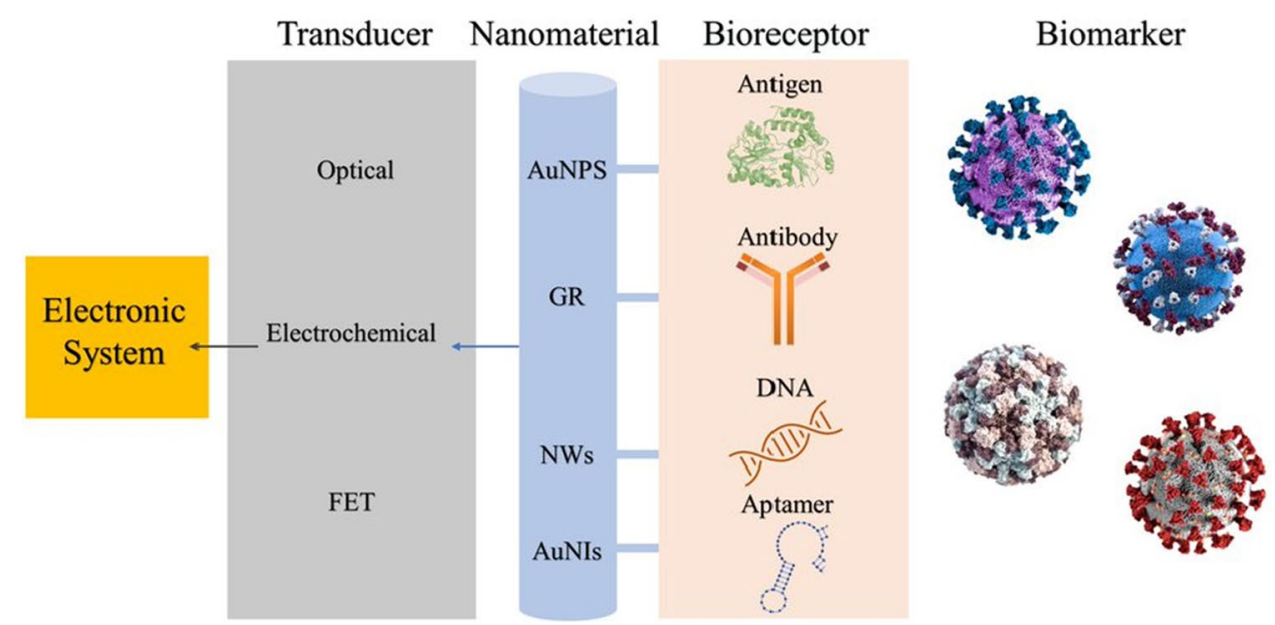


Fig. 7 Paper-based biosensors
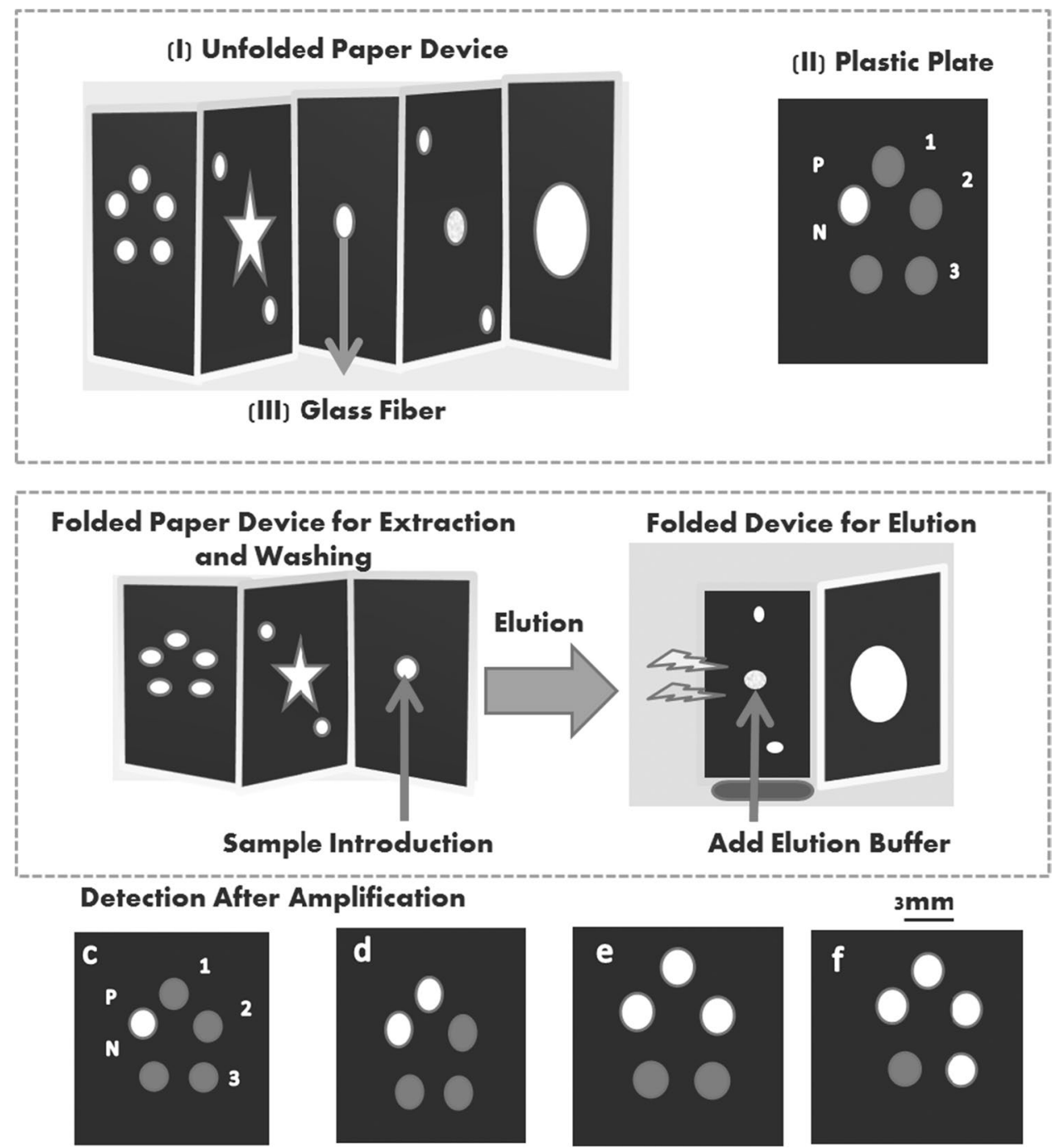

transfer and storing of data and the connection of all relevant parties, all of which entail appropriate resources for technological support and hardware. The exponential advancements of portable networking technologies like $5 \mathrm{G}$ and digital computing, such as "big data" principles and "block chain," increase data transfer and exchange speed and performance. Furthermore, the comprehensive mobile and network application required for them decreases the expense of data processing and transfer. Scientists and medical networks will have the ability to collect and process data with an efficient portable device with sensors/biosensors and wireless links (Perkel 2017).

In addition, the MHealth method will improve productivity by automating inventory and supply chain processes, reduction of workload and paper-related mistakes, and avoiding item loss (Namisango et al. 2016). MHealth has shown its effectiveness in reacting to certain infectious diseases on the media, clinical, and public health. Detailed online prevention, evaluation, and health plan were presented in a report from the UK (Estcourt et al. 2017). Clinical consultations were conducted online for chlamydia patients who had a link between their history and their pharmacies' acquisition of antibiotics. The framework combines partner alerts, health promotion, and automated data treatment to prevent the spread of these potentially asymptomatic contagious diseases.

A biosensor can also be a quick (personality testing), rapid (almost real time) diagnostic tool or detection device to determine the appropriate diagnosis targets for contagious diseases (Bissonnette and Bergeron 2017), and to immediately relay the diagnostic effects to the MHealth system, which would dramatically accelerate the patient's access to treatment and consultation. The identification and implementation of a web-based symptoms and diagnosis reporting application, associated with standardized clinical and epidemiological data gathering, provides a significant potential to increase epidemic monitoring and control (Fallah et al. 2017).

Mobile surveillance can easily identify and handle SARSCoV-2 and intensify the real-time tracking of outbreak areas (Hayward et al. 2014). In addition, community health agencies 
Fig. 8 Biosensor-based MHealth system

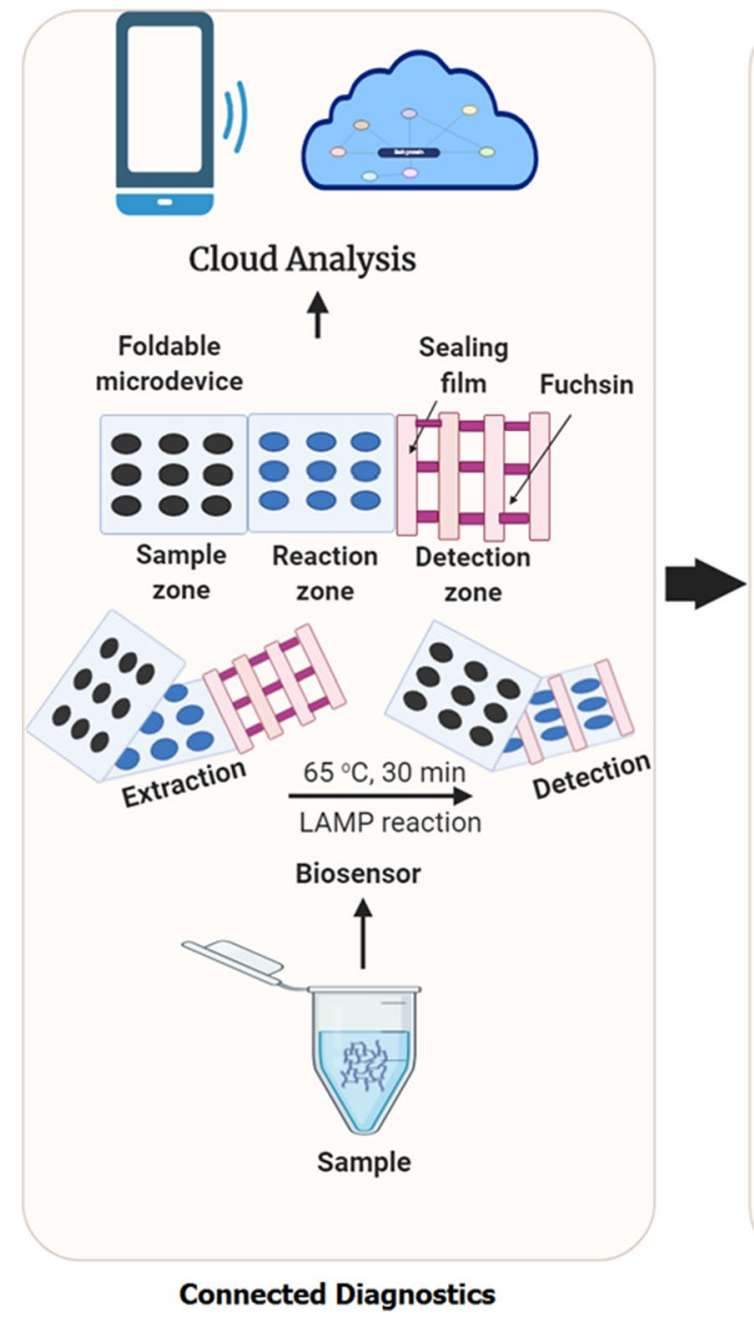

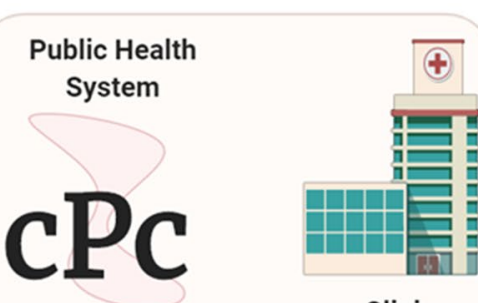

Clinic

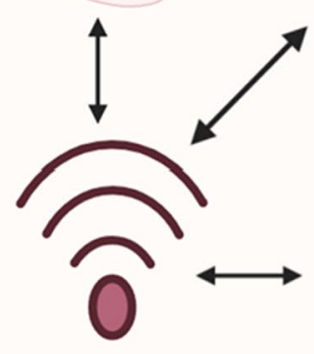

Mobile Network

Healthcare

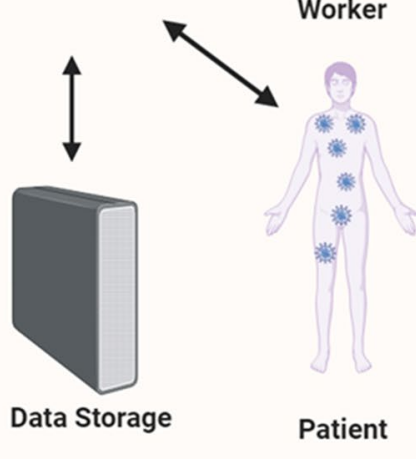

Mobile Health will track the disease with the MHealth system in real time and take corrective steps such as geographic separation and strategic material distribution. The mobile system is easy to learn and can be diagnosed by all mobile system users, including prospective patients, medical personnel, and community health agencies. Health professionals can help direct patients' healthcare, and the community health department can better track the crisis and take steps such as prompt patient segregation, health safety, and public service distribution. In accordance with diagnostic biosensors connected to the internet, the mobile networks provide modern approaches for the detection, surveillance, and management of infectious disorders while enhancing health system performance (Fig. 8).

\section{Data analysis and user's privacy protection challenges}

Embedded data is used for remote patient treatment and diagnosis (e.g., from smartphones and sensors) (Latif et al. 2017a). This can include details on mobility, vital physiological signs, blood glucose, body temperature, and various other signals related to the activity. Ye et. al. (2020) have built a framework that uses real-time information, including demographic data, accessibility data, diseaserelated data, and user-generated social media information. This proposed framework, called satellite, will provide a hierarchical community-level risk evaluation that can guide the creation of strategies to tackle the SARS-CoV-2 pandemic.

Google has also used location data from smartphones to display people's movements during the pandemic (Newton 2020). The design of a low-cost framework for detecting SARS-CoV-2 using smartphone sensors is presented in another study (Maghdid et al. 2020). They suggest the use of radiologists' mobile phones for virus detection. They emphasize that the proposed system is more accurate as it uses multi-readings that can capture signs related to the illness from multiple sensing instruments. Another latest study (Ferretti et al. 2020) concluded that SARS-CoV-2's spread is too rapid for manual contact tracing to be contained. Disease monitoring applications (Yoneki and Crowcroft 2014) use contact/location sensor data to address this. 
The COVID Symptom-Tracking-Software and the COVID-Near-You- Service are the simplest ones that aim to understand the spread of the disease, particularly mild cases that are not frequently checked in the laboratory. Others, such as Stay-Home-Safe in Hong Kong and the HomeQuarantine-App in Poland (Cyfryzacji 2020), aims to track whether people follow quarantine rules (via geofencing). If they have come into touch with anybody infected, more sophisticated technologies will alert users. For example, there are many common softwares such as China's Close-ContactDetector- App as has been mentioned by (Kamel Boulos and Geraghty 2020), China's QR health code complementary system (Ye 2020), Singapore's Trace-Together-App. (Lai et al. 2021), and Israel's HaMagen-App. (Cohen 2020). In the above apps, we remember that one important problem is the security of consumer privacy (Calvo et al. 2020; Cho et al. 2020a). Uploading contact data for server-side computing, for example, might build a national social relationship database, particularly in countries where the user can be mandatory. Decentralized Privacy-Preserving Proximity Tracing (DP-3T) (Troncoso et al. 2020) was proposed to address this. This is a smartphone app for users who might have recently come in touch with an infected user that delivers privacypreserving warnings. Similar features based on homomorphic encryption are provided by TraceSecure (Bell et al. 2020), while Berke et al. provide privacy assurances through the intersection of private sets (Berke et al. 2020). Apple and Google have revealed collaboration focused on Bluetooth to create their privacy-preserving touch tracing standards.

The SARS-CoV-2 pandemic presents specific challenges to communities in developing countries with limited access to healthcare, especially as those people are disproportionately impacted by limited access to public health information (Ahmed et al. 2020; Abouzid et al. 2021) The creation of innovations intended to be internationally inclusive is a key task. This includes an analysis of how certain innovations could affect diverse populations and examine how they could be applied in rural and socially vulnerable regions (Quinn et al. 2014; Latif et al. 2017b; Qadir et al. 2017) and also how they could be misused in such ways. This subsumes a range of functional challenges that naturally differ on the basis of a particular use case. For example, if you are developing a mobile app for touch monitoring, it should be low cost and need limited resources; it should be built with limited network connectivity in mind; it should also accommodate various languages and be open to illiterate users or people with disabilities. We stress that maintaining widespread usability to technical technologies is essential to solving this global pandemic.

\section{Conclusion and future perspective}

Since the SARS-CoV-2 virus is already spreading from one person to another around the globe, it is imperative that this infection can be diagnosed early. Biosensing techniques must be continuously improved in order to meet the rising obstacles in viral diagnosis. It is possible for medical facilities to use the biosensor information to remotely screen the huge populations, such as quarantined individuals, patients confined to long-term care facilities, and those who are at risk in their own homes. The development of biosensors remains challenging, especially with new issues such as data privacy and funding. Therefore, it is essential to proceed with more research on novel biomarkers and mechanisms besides the collaboration with multiple disciple scholars. Future research should focus more on investigating modern properties of materials and study the mechanism and interactions between biomolecules and nanomaterials using nanofilms, electrodes, or new fabricated surfaces.

Acknowledgements Mr. Mohamed Abouzid and Mr. Alhassan Ali Ahmed are participants of STER Internationalisation of Doctoral Schools Programme from NAWA Polish National Agency for Academic Exchange No. PPI/STE/2020/1/00014/DEC/02.

Author contribution El-Sherif D.M., conceptualizing, refining research idea, creating research design, writing manuscript, drawing figures, and revision; Abouzid M., writing manuscript, drawing figures, editing, and revision; Gaballah M.S., writing manuscript; Ahmed A.A., writing manuscript; Adeel M., editing and revision; and Sheta S.M., editing and revision. All authors of this paper have read and approved the final version submitted.

Availability of data and materials Not applicable

\section{Declarations}

Ethics approval and consent to participate Not applicable

Consent for publication Not applicable

Competing interests The authors declare no competing interests.

\section{References}

Abouzid M, El-Sherif DM, Eltewacy NK, et al (2021) Influence of COVID-19 on lifestyle behaviors in the Middle East and North Africa Region: a survey of 5896 individuals. J Transl Med 19:129. https://doi.org/10.1186/s12967-021-02767-9

Ahmed F, Ahmed N, Pissarides C, Stiglitz J (2020) Why inequality could spread COVID-19. Lancet Public Heal 5:e240. https:// doi.org/10.1016/S2468-2667(20)30085-2

Aizawa M (1994) Immunosensors for clinical analysis. Adv Clin Chem 31:247-275. https://doi.org/10.1016/s0065-2423(08) 60337-6

Altintas Z, Gittens M, Guerreiro A et al (2015) Detection of waterborne viruses using high affinity molecularly imprinted polymers. Anal Chem 87:6801-6807. https://doi.org/10.1021/acs. analchem.5b00989

Antiochia R (2020) Nanobiosensors as new diagnostic tools for SARS, MERS and COVID-19: from past to perspectives. Microchim Acta 187:639. https://doi.org/10.1007/s00604-020-04615-x 
Antiochia R (2021) Paper-Based biosensors: frontiers in point-of-care detection of COVID-19 disease. Biosensors 11: https://doi.org/ 10.3390/bios11040110

Arata H, Komatsu H, Hosokawa K, Maeda M (2012) Rapid and sensitive microRNA detection with laminar flow-assisted dendritic amplification on power-free microfluidic chip. PLoS One 7:e48329. https://doi.org/10.1371/journal.pone.0048329

Baek J, Allen PM, Bawendi MG, Jensen KF (2011) Investigation of indium phosphide nanocrystal synthesis using a high-temperature and high-pressure continuous flow microreactor. Angew Chemie Int Ed 50:627-630. https://doi.org/10.1002/anie.20100 6412

Bahl Javaid M, Bagha AK et al (2020) Biosensors applications in fighting COVID-19 pandemic. Apollo Med 17:221. https://doi.org/ 10.4103/AM.AM_56_20

Bahl S, Javaid M, Bagha AK et al (2020) Biosensors applications in fighting COVID-19 pandemic. Apollo Med 17:221. https://doi. org/10.4103/am.am_56_20

Barcelo D (2020) Wastewater-Based Epidemiology to monitor COVID19 outbreak : present and future diagnostic methods to be in your radar. Case Stud Chem Environ Eng 2: https://doi.org/10.1016/j. cscee. 2020.100042

Baxendale IR, Ley S V, Smith CD, Tranmer GK (2006) A flow reactor process for the synthesis of peptides utilizing immobilized reagents, scavengers and catch and release protocols. Chem Commun 4835-4837. https://doi.org/10.1039/B612197G

Beebe DJ, Mensing GA, Walker GM (2002) Physics and applications of microfluidics in biology. Annu Rev Biomed Eng 4:261-286. https://doi.org/10.1146/annurev.bioeng.4.112601.125916

Bell J, Butler D, Hicks C, Crowcroft J (2020) TraceSecure: towards privacy preserving contact tracing. arXiv200404059 [cs]

Berke A, Bakker M, Vepakomma P, et al (2020) Assessing disease exposure risk with location data: a proposal for cryptographic preservation of privacy. arXiv200314412 [cs]

Bhalla N, Pan Y, Yang Z, Payam AF (2020) Opportunities and challenges for biosensors and nanoscale analytical tools for pandemics : COVID-19. ACS Nano. https://doi.org/10.1021/acsnano. 0c04421

Bisoffi M, Hjelle B, Brown DC et al (2008) Detection of viral bioagents using a shear horizontal surface acoustic wave biosensor. Biosens Bioelectron 23:1397-1403. https://doi.org/10.1016/j. bios.2007.12.016

Bissonnette L, Bergeron MG (2017) Portable devices and mobile instruments for infectious diseases point-of-care testing. Expert Rev Mol Diagn 17:471-494. https://doi.org/10.1080/14737159. 2017.1310619

Broeders J, Croux D, Peeters M et al (2013) Mobile application for impedance-based biomimetic sensor readout. IEEE Sens J 13:2659-2665. https://doi.org/10.1109/JSEN.2013.2256346

Buerk DG (1995) Biosensors: theory and applications, 1st editio. CRC Press, Lancaster Penn

Calvo RA, Deterding S, Ryan RM (2020) Health surveillance during covid-19 pandemic. BMJ 369:m1373. https://doi.org/10. 1136/bmj.m1373

Cannon B, Campos AR, Lewitz Z et al (2012) Zeptomole detection of DNA nanoparticles by single-molecule fluorescence with magnetic field-directed localization. Anal Biochem 431:40-47. https://doi.org/10.1016/j.ab.2012.08.017

Chaki NK, Vijayamohanan K (2002) Self-assembled monolayers as a tunable platform for biosensor applications. Biosens Bioelectron 17:1-12. https://doi.org/10.1016/S0956-5663(01)00277-9

Chen C, Wang J (2020) Optical biosensors: an exhaustive and comprehensive review. Analyst. https://doi.org/10.1039/C9AN0 1998G

Chen S-H, Chuang Y-C, Lu Y-C, et al (2009) A method of layerby-layer gold nanoparticle hybridization in a quartz crystal microbalance DNA sensing system used to detect dengue virus. Nanotechnology 20. https://doi.org/10.1088/0957-4484/20/21/ 215501

Cho H, Ippolito D, Yu YW (2020a) Contact tracing mobile apps for COVID-19: privacy considerations and related trade-offs. arXiv

Cho I, Kim DH, Park S (2020) Electrochemical biosensors : perspective on functional nanomaterials for on-site analysis. Biomater Res 24:1-12. https://doi.org/10.1186/s40824-019-0181-y

Choi JR (2020) Development of point-of-care biosensors for COVID19. Front Chem 8:. https://doi.org/10.3389/fchem.2020.00517

Choi K, Ng AHC, Fobel R, Wheeler AR (2012) Digital microfluidics. Annu Rev. Anal Chem 5:413-440. https://doi.org/10.1146/annur ev-anchem-062011-143028

Cohen T (2020) 1.5 million Israelis using voluntary coronavirus monitoring app. Reuters

Cooper MA (2002) Optical biosensors in drug discovery. Nat Rev Drug Discov 1:515-528. https://doi.org/10.1038/nrd838

Cortez NG, Cohen IG, Kesselheim AS (2014) FDA regulation of mobile health technologies. N Engl J Med 371:372-379. https:// doi.org/10.1056/NEJMhle1403384

Cyfryzacji M (2020) Ministerstwo Cyfryzacji Kwarantanna domowa Otwarte Dane Available online: https://dane.gov.pl/pl/application/ application-1243,kwarantanna-domowa. Accessed 21 Oct 2021

Damborsky P, Svital J, Katrlik J (2016) Optical biosensors Pavel Damborsk y. Essays Biochem 60:91-100. https://doi.org/10.1042/ EBC20150010

Danilov A, Tselikov G, Wu F et al (2018) Ultra-narrow surface lattice resonances in plasmonic metamaterial arrays for biosensing applications. Biosens Bioelectron 104:102-112. https://doi.org/ 10.1016/j.bios.2017.12.001

Desmet C, Marquette CA, Blum LJ, Doumèche B (2016) Paper electrodes for bioelectrochemistry: Biosensors and biofuel cells. Biosens Bioelectron 76:145-163. https://doi.org/10.1016/j.bios. 2015.06.052

Dupont D (2011) Analytical Methods I Immunochemical Methods. In: Encyclopedia of Dairy Sciences. pp 177-184

Dyer O (2020) Covid-19: US testing ramps up as early response draws harsh criticism. BMJ 368: https://doi.org/10.1136/bmj.m1167

Ejeian F, Etedali P, Soozanipour A et al (2018) Biosensors for wastewater monitoring : a review. Biosens Bioelectron 118:66-79. https:// doi.org/10.1016/j.bios.2018.07.019

Estcourt CS, Gibbs J, Sutcliffe LJ et al (2017) The eSexual Health Clinic system for management, prevention, and control of sexually transmitted infections: exploratory studies in people testing for Chlamydia trachomatis. Lancet Public Heal 2:e182-e190. https://doi.org/10.1016/S2468-2667(17)30034-8

Fallah MP, Skrip LA, Raftery P et al (2017) Bolstering community cooperation in Ebola resurgence protocols: combining field blood draw and point-of-care diagnosis. Plos Med 14:e1002227e1002227. https://doi.org/10.1371/journal.pmed.1002227

Farsinezhad S, Mohammadpour A, Dalrymple AN et al (2013) Transparent anodic $\mathrm{TiO} 2$ nanotube arrays on plastic substrates for disposable biosensors and flexible electronics. J Nanosci Nanotechnol 13:2885-2891. https://doi.org/10.1166/jnn.2013.7409

Ferretti L, Wymant C, Kendall M, et al (2020) Quantifying SARSCoV-2 transmission suggests epidemic control with digital contact tracing. Science (80-) 368. https://doi.org/10.1126/ science.abb6936

Formisano N, Bhalla N, Caleb Wong LC et al (2015) Multimodal electrochemical and nanoplasmonic biosensors using ferrocene-crowned nanoparticles for kinase drug discovery applications. Electrochem commun 57:70-73. https://doi.org/10. 1016/j.elecom.2015.05.014

Fuerstman MJ, Deschatelets P, Kane R et al (2003) Solving mazes using microfluidic networks. Langmuir 19:4714-4722. https:// doi.org/10.1021/la030054x 
Gaur S, Dumyati G, Nace DA, Jump RLP (2020) Unprecedented solutions for extraordinary times: helping long-term care settings deal with the COVID-19 pandemic. Infect Control Hosp Epidemiol 41:729-730. https://doi.org/10.1017/ice.2020.98

Gautschi G (2002) Piezoelectric sensors. In: Piezoelectric Sensorics. pp 73-91

Ge X, Asiri AM, Du D et al (2014) Nanomaterial-enhanced paperbased biosensors. TrAC Trends Anal Chem 58:31-39. https:// doi.org/10.1016/j.trac.2014.03.008

Geißler D, Charbonnière LJ, Ziessel RF et al (2010) Quantum dot biosensors for ultrasensitive multiplexed diagnostics. Angew Chemie Int Ed 49:1396-1401. https://doi.org/10.1002/anie. 200906399

Gibson TD, Hulbert JN, Parker SM et al (1992) Extended shelf life of enzyme-based biosensors using a novel stabilization system. Biosens Bioelectron 7:701-708. https://doi.org/10.1016/09565663(92)85052-C

Gorkin R, Park J, Siegrist J et al (2010) Centrifugal microfluidics for biomedical applications. Lab Chip 10:1758-1773. https://doi. org/10.1039/B924109D

Green N, Alexander H, Olson A et al (1982) Immunogenic structure of the influenza virus hemagglutinin. Cell 28:477-487. https:// doi.org/10.1016/0092-8674(82)90202-1

Hall DA, Gaster RS, Makinwa K et al (2013) A 256 pixel magnetoresistive biosensor microarray in $0.18 \mu \mathrm{m}$ CMOS. IEEE J Solid-State Circuits 48:1290-1301. https://doi.org/10.1109/ JSSC. 2013.2245058

Hall DA, Gaster RS, Osterfeld SJ et al (2010) GMR biosensor arrays: correction techniques for reproducibility and enhanced sensitivity. Biosens Bioelectron 25:2177-2181. https://doi.org/10. 1016/j.bios.2010.01.039

Han JH, Lee D, Chew CHC et al (2016) A multi-virus detectable microfluidic electrochemical immunosensor for simultaneous detection of $\mathrm{H} 1 \mathrm{~N} 1, \mathrm{H} 5 \mathrm{~N} 1$, and $\mathrm{H} 7 \mathrm{~N} 9$ virus using $\mathrm{ZnO}$ nanorods for sensitivity enhancement. Sensors Actuators, B Chem 228:36-42. https://doi.org/10.1016/j.snb.2015.07.068

Han YD, Chun HJ, Yoon HC (2020) Low-cost point-of-care biosensors using common electronic components as transducers. BioChip J 14:32-47. https://doi.org/10.1007/s13206-020-4104-8

Hannah S, Al-Hatmi M, Gray L, Corrigan DK (2020) Low-cost, thin-film, mass-manufacturable carbon electrodes for detection of the neurotransmitter dopamine. Bioelectrochemistry 133:107480. https://doi.org/10.1016/j.bioelechem.2020. 107480

Harrison DJ, Manz A, Fan Z et al (1992) Capillary electrophoresis and sample injection systems integrated on a planar glass chip. Anal Chem 64:1926-1932. https://doi.org/10.1021/ac00041a030

Hayward AC, Fragaszy EB, Bermingham A et al (2014) Comparative community burden and severity of seasonal and pandemic influenza: results of the Flu Watch cohort study. Lancet Respir Med 2:445-454

Huang JC, Chang Y-F, Chen K-H et al (2009) Detection of severe acute respiratory syndrome (SARS) coronavirus nucleocapsid protein in human serum using a localized surface plasmon coupled fluorescence fiber-optic biosensor. Biosens Bioelectron 25:320-325. https://doi.org/10.1016/j.bios.2009.07.012

Huang X, Xu D, Chen J et al (2018) Smartphone-based analytical biosensors. Analyst 143:5339-5351. https://doi.org/10.1039/c8an0 $1269 \mathrm{e}$

Imran S, Ahmadi S, Kerman K (2021) Electrochemical biosensors for the detection of SARS-CoV-2 and other viruses. micromachines $12: 174$

B J, Chanda K, Mm B (2018) Biosensors for pathogen surveillance. Environ Chem Lett 16:1325-1337. https://doi.org/10.1007/ s10311-018-0759-y
Jin YH, Cai L, Cheng ZS et al (2020) A rapid advice guideline for the diagnosis and treatment of 2019 novel coronavirus (2019-nCoV) infected pneumonia (standard version). Mil Med Res 7:4. https:// doi.org/10.1186/s40779-020-0233-6

Kamel Boulos MN, Geraghty EM (2020) Geographical tracking and mapping of coronavirus disease COVID-19/severe acute respiratory syndrome coronavirus 2 (SARS-CoV-2) epidemic and associated events around the world: how 21 st century GIS technologies are supporting the global fight against outbreaks and epidemics. Int J Health Geogr 19:8. https://doi.org/10.1186/ s12942-020-00202-8

Kamikawa TL, Mikolajczyk MG, Kennedy M et al (2012) Pandemic influenza detection by electrically active magnetic nanoparticles and surface plasmon resonance. IEEE Trans Nanotechnol 11:8896. https://doi.org/10.1109/TNANO.2011.2157936

Kirby BJ (2010) Micro- and nanoscale fluid mechanics: transport in microfluidic devices, 1st editio. Cambridge University Press

Kirimli CE, Shih W-H, Shih WY (2014) DNA hybridization detection with $100 \mathrm{zM}$ sensitivity using piezoelectric plate sensors with an improved noise-reduction algorithm. Analyst 139:2754-2763. https://doi.org/10.1039/c4an00215f

Kong LX, Perebikovsky A, Moebius J et al (2015) Lab-on-a-CD: a fully integrated molecular diagnostic system. J Lab Autom. https://doi.org/10.1177/2211068215588456

Kröger S, Turner APF (1997) Solvent-resistant carbon electrodes screen printed onto plastic for use in biosensors. Anal Chim Acta 347:9-18. https://doi.org/10.1016/S0003-2670(96)00634-4

Kudr J, Michalek P, Ilieva L et al (2021) COVID-19: a challenge for electrochemical biosensors. Trends Anal Chem 136:116192

Lai SHS, Tang CQY, Kurup A, Thevendran G (2021) The experience of contact tracing in Singapore in the control of COVID-19: highlighting the use of digital technology. Int Orthop 45:65-69. https://doi.org/10.1007/s00264-020-04646-2

Langone M, Petta L, Cellamare CM et al (2021) SARS-CoV-2 in water services: presence and impacts. Environ Pollut 268:115806. https://doi.org/10.1016/j.envpol.2020.115806

Latif S, Qadir J, Farooq S, Imran MA (2017) How 5G wireless (and concomitant technologies) will revolutionize healthcare? Futur Internet 9:93. https://doi.org/10.3390/fi9040093

Latif S, Rana R, Qadir J et al (2017) Mobile health in the developing world: review of literature and lessons from a case study. IEEE Access 5:11540-11556. https://doi.org/10.1109/ACCESS.2017. 2710800

Lee J, Ahmed SR, Oh S et al (2015) A plasmon-assisted fluoro-immunoassay using gold nanoparticle-decorated carbon nanotubes for monitoring the influenza virus. Biosens Bioelectron 64:311-317. https://doi.org/10.1016/j.bios.2014.09.021

Li L, Pan L, Ma Z et al (2018) All inkjet-printed amperometric multiplexed biosensors based on nanostructured conductive hydrogel electrodes. Nano Lett 18:3322-3327. https://doi.org/10.1021/acs. nanolett.8b00003

Li Z, Yi Y, Luo X et al (2020) Development and clinical application of a rapid IgM-IgG combined antibody test for SARS-CoV-2 infection diagnosis. J Med Virol 92:1518-1524. https://doi.org/ 10.1002/jmv. 25727

Ligler FS, Breimer M, Golden JP et al (2002) Integrating waveguide biosensor. Anal Chem 74:713-719. https://doi.org/10. 1021/ac015607s

Loncaric C, Tang Y, Ho C et al (2012) A USB-based electrochemical biosensor prototype for point-of-care diagnosis. Sensors Actuators, B Chem 161:908-913. https://doi.org/10.1016/j. snb.2011.11.061

Lu G, Hu Y, Wang Q et al (2013) Molecular basis of binding between novel human coronavirus MERS-CoV and its receptor CD26. Nature 500:227-231. https://doi.org/10.1038/nature12328 
Ma J, Du M, Wang C et al (2021) Advances in airborne microorganisms detection using biosensors: a critical review. Front Environ Sci Eng 15:47. https://doi.org/10.1007/s11783-021-1420-8

Ma R-M, Oulton RF (2019) Applications of nanolasers. Nat Nanotechnol 14:12-22. https://doi.org/10.1038/s41565-018-0320-y

Maddali AH, Miles CE, Kohn J, Carroll DMO (2020) Optical biosensors for virus detection: prospects for SARS-CoV-2/COVID19. ChemBioChem. https://doi.org/10.1002/cbic.202000744

Maghdid HS, Ghafoor KZ, Sadiq AS, et al (2020) A novel AI-enabled framework to diagnose coronavirus COVID 19 using smartphone embedded sensors: design study. arXiv200307434 [cs, q-bio]

Mahari S, Roberts A, Shahdeo D, Gandhi S (2020) eCovSens-Ultrasensitive novel in-house built printed circuit board based electrochemical device for rapid detection of nCovid-19. bioRxiv. https://doi.org/10.1101/2020.04.24.059204

Manz A, Graber N, Widmer HM (1990) Miniaturized total chemical analysis systems: a novel concept for chemical sensing. Sensors Actuators B Chem 1:244-248. https://doi.org/10.1016/09254005(90)80209-I

Manz A, Harrison DJ, Verpoorte EMJ et al (1992) Planar chips technology for miniaturization and integration of separation techniques into monitoring systems. Capillary electrophoresis on a chip. J Chromatogr 593:253-258. https://doi.org/10.1016/00219673(92)80293-4

Manzanares Palenzuela CL, Pumera M (2018) (Bio)Analytical chemistry enabled by 3D printing: sensors and biosensors. TrAC Trends Anal Chem 103:110-118. https://doi.org/10.1016/j.trac.2018.03. 016

Mao C, Liu A, Cao B (2009) Virus-based chemical and biological sensing. Angew. Chemie - Int. Ed. 48:6790-6810

Mao K, Zhang H, Yang Z (2020) An integrated biosensor system with mobile health and wastewater-based epidemiology (iBMW) for COVID-19 pandemic. Biosens Bioelectron 169:112617. https:// doi.org/10.1016/j.bios.2020.112617

Mao K, Zhang H, Yang Z (2020) Biosensors and bioelectronics an integrated biosensor system with mobile health and wastewaterbased epidemiology (iBMW) for COVID-19 pandemic. Biosens Bioelectron 169:112617. https://doi.org/10.1016/j.bios.2020. 112617

Mark D, Haeberle S, Roth G et al (2010) Microfluidic lab-on-a-chip platforms: requirements, characteristics and applications. Chem Soc Rev 39:1153-1182. https://doi.org/10.1039/B820557B

Martinez AW, Phillips ST, Butte MJ, Whitesides GM (2007) Patterned paper as a platform for inexpensive, low-volume, portable bioassays. Angew Chemie Int Ed 46:1318-1320. https://doi.org/10. 1002/anie. 200603817

Maryam G, Mollazadeh-Bajestani M, Moztarzadeh F et al (2021) An overview of the use of biomaterials, nanotechnology, and stem cells for detection and treatment of COVID-19: towards a framework to address future global pandemics. Emergent Mater 4:19-34. https://doi.org/10.1007/s42247-020-00143-9

Mehta S, Zhang Y, Roth RH et al (2018) Single-fluorophore biosensors for sensitive and multiplexed detection of signalling activities. Nat Cell Biol 20:1215-1225. https://doi.org/10.1038/ s41556-018-0200-6

Miodek A, Regan EM, Bhalla N et al (2015) Optimisation and characterisation of anti-fouling ternary SAM layers for impedancebased aptasensors. Sensors (Basel) 15:25015-25032. https://doi. org/10.3390/s151025015

Mitsakakis K, Gizeli E (2011) Detection of multiple cardiac markers with an integrated acoustic platform for cardiovascular risk assessment. Anal Chim Acta 699:1-5. https://doi.org/10.1016/j. aca.2011.05.016

Mohankumar P, Ajayan J, Mohanraj T, Yasodharan R (2021) Recent developments in biosensors for healthcare and biomedical applications: a review. Measurement 167:108293
Muratsugu M, Ohta F, Miya Y et al (2002) Quartz crystal microbalance for the detection of microgram quantities of human serum albumin: relationship between the frequency change and the mass of protein adsorbed. Anal Chem 65:2933-2937. https://doi.org/10. 1021/ac00068a036

Nam J-M, Thaxton CS, Mirkin CA (2003) Nanoparticle-based bio-bar codes for the ultrasensitive detection of proteins. Science (80- ) 301:1884-1886. https://doi.org/10.1126/science.1088755

Namisango E, Ntege C, Luyirika EBK et al (2016) Strengthening pharmaceutical systems for palliative care services in resource limited settings: piloting a mHealth application across a rural and urban setting in Uganda. BMC Palliat Care 15:20. https://doi.org/10. 1186/s12904-016-0092-9

Narita F, Wang Z, Kurita $\mathrm{H}$ et al (2021) A review of piezoelectric and magnetostrictive biosensor materials. Adv Mater 33:2005448. https://doi.org/10.1002/adma.202005448

Nemudryi A, Nemudraia A, Wiegand T et al (2020) Temporal detection and phylogenetic assessment of SARS-CoV-2 in municipal wastewater. Cell Reports Med 1:100098. https://doi.org/10. 1016/j.xcrm.2020.100098

Newton C (2020) Google uses location data to show which places are complying with stay-at-homeorders — and which aren't - The Verge Available online: https://www.theverge.com/2020/4/3/ 21206318/googlelocation- data-mobility-reports-covid-19-priva cy. Accessed 21 Oct 2021

Nidzworski D, Pranszke P, Grudniewska M et al (2014) Universal biosensor for detection of influenza virus. Biosens Bioelectron 59:239-242. https://doi.org/10.1016/j.bios.2014.03.050

Nomngongo PN, Ngila JC, Msagati TAM et al (2012) Determination of selected persistent organic pollutants in wastewater from landfill leachates, using an amperometric biosensor. Phys Chem Earth 50-52:252-261. https://doi.org/10.1016/j.pce.2012.08.001

Osman DI, El-Sheikh SM, Sheta SM, et al (2019) Nucleic acids biosensors based on metal-organic framework (MOF): paving the way to clinical laboratory diagnosis. BiosensBioelectron 141: https:// doi.org/10.1016/j.bios.2019.111451

Pashchenko O, Shelby T, Banerjee T, Santra S (2018) A comparison of optical, electrochemical, magnetic, and colorimetric pointof-care biosensors for infectious disease diagnosis. ACS Infect Dis 4:1162-1178. https://doi.org/10.1021/acsinfecdis.8b00023

Perkel JM (2017) Pocket laboratories. Nature 545:119-121. https://doi. org/10.1038/545119a

Pineda MF, Chan LLY, Choi CJ et al (2009) Rapid Specific and labelfree detection of porcine rotavirus using photonic crystal biosensors. IEEE Sens J 9:470-477. https://doi.org/10.1109/JSEN. 2009.2014427

Pohanka M (2018) Overview of piezoelectric biosensors, immunosensors and DNA sensors and their applications. Materials (Basel) 11: https://doi.org/10.3390/ma11030448

Puigmartí-Luis J (2014) Microfluidic platforms: a mainstream technology for the preparation of crystals. Chem Soc Rev 43:22532271. https://doi.org/10.1039/C3CS60372E

Puleo CM, Wang T-H (2009) Microfluidic means of achieving attomolar detection limits with molecular beacon probes. Lab Chip 9:1065-1072. https://doi.org/10.1039/B819605B

Qadir J, Mujeeb-U-Rahman M, Rehmani MH et al (2017) IEEE access special section editorial: health informatics for the developing world. IEEE Access 5:27818-27823. https://doi.org/10.1109/ ACCESS.2017.2783118

Qin J, Wheeler AR (2007) Maze exploration and learning in C. elegans. Lab Chip 7:186-192. https://doi.org/10.1039/B613414A

Qiu G, Gai Z, Tao Y et al (2020) Dual-functional plasmonic photothermal biosensors for highly accurate severe acute respiratory syndrome coronavirus 2 detection. ACS Nano 14:5268-5277. https://doi.org/10.1021/acsnano.0c02439 
Quinn J, Frias-Martinez V, Subramanian L (2014) Computational sustainability and artificial intelligence in the developing world. AI Mag 35:36-47. https://doi.org/10.1609/aimag.v35i3.2529

Ramfos I, Blionas S, Birbas A (2014) Architecture of a modular, multichannel readout system for dense electrochemical biosensor microarrays. Meas Sci Technol 26:15701. https://doi.org/10. 1088/0957-0233/26/1/015701

Rasheed PA, Sandhyarani N (2015) A highly sensitive DNA sensor for attomolar detection of the BRCA1 gene: signal amplification with gold nanoparticle clusters. Analyst 140:2713-2718. https:// doi.org/10.1039/C5AN00004A

Riberio VB, Aparecida T, Cordeiro R et al (2020) Biosensors for the detection of respiratory viruses : a review. Talanta Open 2:100007. https://doi.org/10.1016/j.talo.2020.100007

Roda A, Michelini E, Zangheri M et al (2016) Smartphone-based biosensors: a critical review and perspectives. TrAC Trends Anal Chem 79:317-325. https://doi.org/10.1016/j.trac.2015.10.019

Rodriguez GA, Markov P, Cartwright AP et al (2019) Photonic crystal nanobeam biosensors based on porous silicon. Opt Express 27:9536-9549. https://doi.org/10.1364/OE.27.009536

Rose HM, Witte C, Rossella F et al (2014) Development of an antibody-based, modular biosensor for 129Xe NMR molecular imaging of cells at nanomolar concentrations. Proc Natl Acad Sci 111:11697-11702. https://doi.org/10.1073/pnas.1406797111

Rossi AM, Wang L, Reipa V, Murphy TE (2007) Porous silicon biosensor for detection of viruses. Biosens Bioelectron 23:741-745. https://doi.org/10.1016/j.bios.2007.06.004

Rowe CA, Tender LM, Feldstein MJ et al (1999) Array biosensor for simultaneous identification of bacterial, viral, and protein analytes. Anal Chem 71:3846-3852. https://doi.org/10.1021/ac981 $425 \mathrm{v}$

Sabaté del Río J, Henry OYF, Jolly P, Ingber DE (2019) An antifouling coating that enables affinity-based electrochemical biosensing in complex biological fluids. Nat Nanotechnol 14:1143-1149. https://doi.org/10.1038/s41565-019-0566-z

Samson R, Navale GR, Dharne MS (2020) Biosensors: frontiers in rapid detection of COVID-19. 3 Biotech 10:1-9. https://doi.org/ 10.1007/s13205-020-02369-0

Seshadri DR, Davies E V, Harlow ER, et al (2020) Wearable sensors for COVID-19: a call to action to harness our digital infrastructure for remote patient monitoring and virtual assessments. Front Digit Heal 2: https://doi.org/10.3389/fdgth.2020.00008

Sethi RS (1994) Transducer aspects of biosensors. Biosens Bioelectron 9:243-264. https://doi.org/10.1016/0956-5663(94)80127-4

Sheta SM, El-Sheikh SM, Abd-Elzaher MM et al (2019) A novel, fast, high sensitivity biosensor for supporting therapeutic decisions and onset actions for chest pain cases $\dagger$. RSC Adv 9:2046320471. https://doi.org/10.1039/c9ra03030a

Sheta SM, El-Sheikh SM, Abd-Elzaher MM, et al (2019b) A novel biosensor for early diagnosis of liver cancer cases using smart nano-magnetic metal-organic framework. Appl Organomet Chem 33. https://doi.org/10.1002/aoc.5249

Shirvalilou R, Milad S, Saman S et al (2021) Application of nanobiotechnology for early diagnosis of SARS-CoV-2 infection in the COVID-19 pandemic. Appl Microbiol Biotechnol 105:26152624. https://doi.org/10.1007/s00253-021-11197-y

Singh S, Kumar V, Kapoor D et al (2021) Detection and disinfection of COVID-19 virus in wastewater Simranjeet. Environ Chem Lett. https://doi.org/10.1007/s10311-021-01202-1

Socorro-Leránoz AB, Santano D, Del Villar I, Matias IR (2019) Trends in the design of wavelength-based optical fibre biosensors (2008-2018). Biosens Bioelectron X 1:100015. https://doi. org/10.1016/j.biosx.2019.100015
Solanki PR, Kaushik A, Agrawal VV, Malhotra BD (2011) Nanostructured metal oxide-based biosensors. NPG Asia Mater 3:17-24. https://doi.org/10.1038/asiamat.2010.137

Squires TM, Quake SR (2005) Microfluidics: fluid physics at the nanoliter scale. Rev Mod Phys 77:977-1026. https://doi.org/10.1103/ RevModPhys.77.977

Stumpf F, Schwemmer F, Hutzenlaub T et al (2015) LabDisk with complete reagent prestorage for sample-to-answer nucleic acid based detection of respiratory pathogens verified with influenza A H3N2 virus. Lab Chip 16:199-207. https://doi.org/10.1039/ C5LC00871A

Suleman S, Shukla SK, Malhotra N et al (2021) Point of care detection of COVID-19: advancement in biosensing and diagnostic methods. Chem Eng J 414:128759

Sun AC, Yao C, A.g V, Hall DA, (2016) An efficient power harvesting mobile phone-based electrochemical biosensor for point-ofcare health monitoring. Sensors Actuators B Chem 235:126-135. https://doi.org/10.1016/j.snb.2016.05.010

Sun F, Ganguli A, Nguyen J et al (2020) Smartphone-based multiplex 30-minute nucleic acid test of live virus from nasal swab extract. Lab Chip 20:1621-1627. https://doi.org/10.1039/D0LC00304B

Tabeling P, Chen S (2005) Introduction to microfluidics. Oxford University Press, Oxford, New York

Takemura K, Adegoke O, Takahashi N et al (2017) Versatility of a localized surface plasmon resonance-based gold nanoparticlealloyed quantum dot nanobiosensor for immunofluorescence detection of viruses. Biosens Bioelectron 89:998-1005. https:// doi.org/10.1016/j.bios.2016.10.045

Tan SH, Maes F, Semin B et al (2014) The microfluidic jukebox. Sci Rep 4:4787. https://doi.org/10.1038/srep04787

Tekin HC, Cornaglia M, Gijs MAM (2013) Attomolar protein detection using a magnetic bead surface coverage assay. Lab Chip 13:1053-1059. https://doi.org/10.1039/C3LC41285G

Tetteh EK, Amankwa MO, Armah EK (2020) Fate of COVID-19 Occurrences in wastewater systems : emerging detection and treatment technologies - a review. Water 12. Water 12:2680. https://doi.org/10.3390/w12102680

Tort N, Salvador JP, Marco MP (2017) Multimodal plasmonic biosensing nanostructures prepared by DNA-directed immobilization of multifunctional DNA-gold nanoparticles. Biosens Bioelectron 90:13-22. https://doi.org/10.1016/j.bios.2016.11.022

Troncoso C, Payer M, Hubaux J-P, et al (2020) Decentralized privacypreserving proximity tracing. arXiv200512273 [cs]

Varshney M, Li Y (2009) Interdigitated array microelectrodes based impedance biosensors for detection of bacterial cells. Biosens Bioelectron 24:2951-2960. https://doi.org/10.1016/j.bios.2008. 10.001

Verma N, Singh AK (2013) Development of biological oxygen demand biosensor for monitoring the fermentation industry effluent. ISRN Biotechnol Article ID 236062:6 pages. https://doi.org/10. $5402 / 2013 / 236062$

Vidic J, Manzano M (2021) Electrochemical biosensors for rapid pathogen detection. Curr Opin Electrochem. https://doi.org/10. 1016/j.coelec.2021.100750

Wang B, Barahona M, Buck M (2013) A modular cell-based biosensor using engineered genetic logic circuits to detect and integrate multiple environmental signals. Biosens Bioelectron 40:368376. https://doi.org/10.1016/j.bios.2012.08.011

Wang J, Shen J, Ye D et al (2020) Disinfection technology of hospital wastes and wastewater: suggestions for disinfection strategy during coronavirus Disease 2019 (COVID-19) pandemic in China. Environ Pollut 262:114665. https://doi.org/10.1016/j.envpol. 2020.114665 
Wang L, Anderson DE (2019) Viruses in bats and potential spillover to animals and humans. Curr Opin Virol 34:79-89. https://doi. org/10.1016/j.coviro.2018.12.007

Wang R, Lin J, Lassiter K et al (2011) Evaluation study of a portable impedance biosensor for detection of avian influenza virus. J Virol Methods 178:52-58. https://doi.org/10.1016/j.jviromet. 2011.08.011

Weis W, Brown JH, Cusack S et al (1988) Structure of the influenza virus haemagglutinin complexed with its receptor, sialic acid. Nature 333:426-431. https://doi.org/10.1038/333426a0

WHO (2020) Water, sanitation, hygiene and waste management for the COVID-19 virus. World Heal Organ 1-9

Wood CS, Thomas MR, Budd J et al (2019) Taking connected mobilehealth diagnostics of infectious diseases to the field. Nature 566:467-474

Wu AR, Neff NF, Kalisky T et al (2014) Quantitative assessment of single-cell RNA-sequencing methods. Nat Methods 11:41-46. https://doi.org/10.1038/nmeth.2694

Wu K, Klein T, Krishna VD et al (2017) Portable GMR handheld platform for the detection of influenza a virus. ACS Sensors 2:1594-1601. https://doi.org/10.1021/acssensors.7b00432

Xi X, Wu D, Ji W et al (2020) Manipulating the sensitivity and selectivity of OECT-based biosensors via the surface engineering of carbon cloth gate electrodes. Adv Funct Mater 30:1905361. https://doi.org/10.1002/adfm.201905361

Xiao F, Li Y, Zan X et al (2012) Growth of metal-metal oxide nanostructures on freestanding graphene paper for flexible biosensors. Adv Funct Mater 22:2487-2494. https://doi.org/10.1002/ADFM. 201200191

Xu L, Li D, Ramadan S et al (2020) Facile biosensors for rapid detection of COVID-19. Biosens Bioelectron 170:112673. https://doi. org/10.1016/j.bios.2020.112673

Yamashita T, Ookawa N, Ishida M et al (2016) A novel open-Type biosensor for the in-situ monitoring of biochemical oxygen demand in an aerobic environment. Sci Rep 6:1-2. https://doi.org/10. 1038/srep38552

Ye J (2020) China's QR health code system brings relief for some... and new problems. South China Morning Post
Ye Y, Hou S, Fan Y, et al (2020) \$lalpha\$-Satellite: an AI-driven system and benchmark datasets for hierarchical community-level risk assessment to help combat COVID-19. arXiv200312232 [cs, q-bio]

Yildirim N, Li D, Long F, Gu AZ (2013) Direct detection of adenovirus in environmental waste waters by portable optical fiber sensor platform. In: Proceedings of IEEE Sensors. IEEE Computer Society

Yoneki E, Crowcroft J (2014) EpiMap: towards quantifying contact networks for understanding epidemiology in developing countries. Ad Hoc Networks 13:83-93. https://doi.org/10.1016/j.adhoc. 2012.06.003

Yoo E-H, Lee S-Y (2010) Glucose biosensors: an overview of use in clinical practice. Sensors (Basel) 10:4558-4576. https://doi.org/ $10.3390 / \mathrm{s} 100504558$

Zaidi SA (2021) An overview of bio-inspired intelligent imprinted polymers for virus determination. Biosensors 11. https://doi.org/ 10.3390/bios11030089

Zamani P, Sajedi RH, Hosseinkhani S et al (2016) A luminescent hybridoma-based biosensor for rapid detection of $\mathrm{V}$. cholerae upon induction of calcium signaling pathway. Biosens Bioelectron 79:213-219. https://doi.org/10.1016/j.bios.2015.12.018

Zengerle R, Grötzinger K (2020) State funds the development of rapid tests for coronavirus. In: Hahn-Schickard-Gesellschaft für Angew. Forsch. e.V.

Zhou N, Wang J, Chen T et al (2006) Enlargement of gold nanoparticles on the surface of a self-assembled monolayer modified electrode: a mode in biosensor design. Anal Chem 78:5227-5230. https://doi.org/10.1021/ac0605492

Zuo P, Li X, Dominguez DC, Ye B-C (2013) A PDMS/paper/glass hybrid microfluidic biochip integrated with aptamer-functionalized graphene oxide nano-biosensors for one-step multiplexed pathogen detection. Lab Chip 13:3921-3928. https://doi.org/10. 1039/C3LC50654A

Publisher's Note Springer Nature remains neutral with regard to jurisdictional claims in published maps and institutional affiliations. 